\title{
Determinants of Stock Market Volatility and Risk Premia
}

\author{
by \\ Mordecai Kurz, Hehui Jin and Maurizio Motolese \\ Stanford University and Catholic University of Milan. \\ October 17, 2003
}

\begin{abstract}
This paper shows the dynamics of diverse beliefs is the primary propagation mechanism of volatility in asset markets. In a model with a stock and bond market in which agents hold diverse Rational Belief (see Kurz (1994)) our economy replicates well the empirical record of (i) the first two moments of the price/dividend ratio, the risky return on stocks, the riskless interest rate and the equity premium; (ii) the Sharp ratio and the correlation between risky returns and the aggregate consumption growth rate; (iii) the predictability of stock returns and the price/dividend ratio, as reported in the literature, expressed by: (a) Variance Ratio statistic for long lags, (b) autocorrelation of these two variables, (c) mean reversion of the risky returns and the power of the price/dividend ratio to predict the risky return at different horizons. Also, our model predicts and explains the presence of stochastic volatility in equilibrium asset prices and asset returns.

The tool used to model diverse rationalizable beliefs is the market state of belief. This index identifies the distribution of conditional probability functions of agents. We show there are two simple properties of the diversity of beliefs which drive market volatility: (i) rationalizable over confidence, described by amplification of an agent's probability belief, which generates densities with fat tails, and (ii) rationalizable asymmetry in frequencies of bull or bear states. Diverse price forecasts is essential to our theory. Since at each date agents forecast the market states of belief, in our general equilibrium context this tool is simply a formal method to allow agents to use the equilibrium map but make heterogenous but rationalizable price forecasts.

JEL classification: G1; G12; E43; E44; D58; D84.
\end{abstract}

Keywords: expectations; market volatility; equity risk premium; riskless interest rate; propagation mechanism; heterogenous beliefs; over confidence; Rational Belief; optimism; pessimism; non stationarity; empirical distribution;

For Correspondence:

Mordecai Kurz, Joan Kenney Professor of Economics

Department of Economics, Landau Building

Stanford University

Stanford, CA. 94305 - 6072

Email: mordecai@stanford.edu 


\title{
Determinants of Stock Market Volatility and Risk Premia ${ }^{1}$
}

by

\author{
Mordecai Kurz ${ }^{2}$, Hehui Jin $^{3}$ and Maurizio Motolese \\ September 25, 2003
}

\section{Introduction}

The economic forces which determine equilibrium market volatility and risk premia are probably the most debated topics in the analysis of financial markets. Part of the debate is the empirical evidence revealing market "anomalies" which have challenged students of the subject. Consumption-based asset pricing theory, closely aligned with dynamic general equilibrium theory, has had a profound impact on our view of financial markets and of asset price determination process. Early work of Leroy (1973), Lucas (1978), Breeden (1979), Grossman and Shiller (1981), Mehra and Prescott (1985), Hansen and Singleton (1983) and others show how intertemporal optimization of investor incorporates a subtle relationship between consumption growth and asset returns. However, when examined empirically, this same simple relationship fails to provide a correct quantitative measure of the risk premia of different asset categories. The Equity Premium Puzzle (see, Mehra and Prescott (1985)) is a special case of the general fact that assets prices are more volatile than can be explained by "fundamental" shocks and the observed premia on risky assets are much larger than predicted by the theory.

Risk premia which are difficult to account for are not confined to the consumption based asset pricing theory; they arise while employing diverse models of asset pricing. Three examples will illustrate. The Expectations Hypothesis is rejected by most studies of the term structure (e.g. Backus, Gregory and Zin (1989), Campbell and Shiller (1991)) implying excessive risk premium on longer maturity debt. Foreign exchange markets exhibit a "Forward Discount Bias" (see Froot and

\footnotetext{
${ }^{1}$ This research was supported by a grant of the Smith Richardson Foundation to the Stanford Institute for Economic Policy Research (SIEPR). We thank Kenneth Judd for constant advice which was crucial at several points in the development of this work. We also thank Ho-Mou Wu for comments on an earlier draft.

${ }^{2}$ Department of Economics, Stanford University, Stanford, CA. 94305-6072.

${ }^{3}$ Department of Economics, Stanford University, Stanford, CA. 94305-6072.

${ }^{4}$ Istituto di Politica Economica, Universitá Cattolica di Milano, Via Necchi 5, 20123, Milano, Italy.
} 
Frankel (1989) and Engel (1996)) which implies an unaccounted for risk premium for holding foreign exchange. The market pricing of derivative securities generate excess implied volatility of the underlying securities which results in unaccounted for risk premia associated with holding of derivative assets. Many writers treat these type of phenomena as unusual anomalies and give them distinct labels, presuming standard models of capital asset pricing theory could then account for all normal premia. Our perspective is different.

This paper contributes to a unified theory of asset price volatility and the determinants of risk premia. We propose that risk premia are primarily determined by the structure of agents' expectations called "the market state of belief." Heterogeneity of belief is then the root cause of price volatility and the main factor explaining risk premia. Our theory incorporates agents who may be "bulls" or "bears." An agent is a bull at date $t$ if he expects the date $t+1$ rate of return on his investment to be higher than normal, where "normal" returns are defined by the empirical distribution of past returns. A date $t$ bear expects returns at $t+1$ to be lower than normal.

Agents in our economy do not hold Rational Expectations (in short RE) since the environment is dynamically changing hence non stationary, and the true probability of events is unknown. In such an economy agents construct their own subjective models of the market. Some may consider our agents irrational. We think it is not reasonable to require agents to know what they cannot know. Hence, in a dynamically complex economy there is a wide gulf between the All Knowing Rational Expectations agent and irrational behavior which can easily be improved upon. Our agents hold diverse but rational beliefs in accord with the theory of Rational Belief Equilibrium (in short, RBE) due to Kurz [1994] and explored in papers included in Kurz [1996], [1997]. We believe this rationality principle strikes a proper balance between RE and irrational behavior and to assist readers unfamiliar with this theory, we briefly explain it.

\section{The Rational Belief Principle}

"Rational Belief" (in short, RB) is not a theory which demonstrates that rational agents should adopt any particular belief. Indeed, since the RB theory explains the observed belief heterogeneity, it would be a contradiction to propose that a particular belief is the "correct" belief a rational agents must adopt. The RB theory starts by observing that the true stochastic law of 
motion of the economy is non-stationary with structural breaks and complex dynamics, where the probability law of the process is not known by anyone. Agents have a long history of past data generated by the process which they use to compute relative frequencies of finite dimensional events and correlation among observed variables. With this knowledge they compute the empirical distribution and use it to construct an empirical probability measure over sequences. Since these computations are based on the law of large numbers, the estimated probability model is stationary. Within the RB theory it is called the "empirical measure" or the "stationary measure."

In contrast with a Rational Expectations Equilibrium (in short, REE) where the true law of motion is common knowledge, agents in an RBE form subjective and diverse beliefs based only on market data. Hence, any principle on the basis of which agents can be judged as rational must be based on the data rather than on the true but unknown law of motion. Since a "belief" is a model of the economy together with a probability over sequences of variables, such a model can be used to generate artificial data. With simulated data an agent can compute the empirical distribution of observed variables and the empirical probability measure the model implies. Based on these facts, the RB theory proposes a simple Principle of Rationality. It says that if the agent's model generates an empirical distribution which is not the same as the one known for the economy, then the agent's model (i.e. "belief") is declared irrational. The converse also holds: for a belief to be rational its simulated data must reproduce the known empirical distribution of the observed variables. The RB rationality principle declares a belief to be rational if it is a model which cannot be disproved with the available empirical evidence. Since diverse theories are compatible with the evidence, this rationality principle permits diversity of beliefs among equally informed rational agents. Agents who hold rational beliefs may make "incorrect" forecasts at date $\mathrm{t}$ but must be correct, on average. Date $t$ forecasts may deviate from the forecasts implied by the empirical probability. However, the $\mathrm{RB}$ rationality principle requires the time average of forecasts to agree with the forecast implied by the empirical frequencies. It thus follows as a theorem that agents who hold rational beliefs must have forecast functions which vary over time. The tool we use to describe the beliefs of agents in an economy is the "market state of belief." It is a state variable which uniquely defines the vector of conditional probability functions held by agents in the economy at each date $t$.

The RB rationality principle is compatible with several known theories. An REE is a special 
case of an RBE and so are the REE with sunspots. Most models of Bayesian learning satisfy the $\mathrm{RB}$ rationality principle. Also, several models of Behavioral Economics satisfy this principle for some parameter values.

Earlier papers using the RBE rationality principle have also argued that agents' beliefs are central to explaining the volatility of financial markets (e.g. Kurz (1996), (1997a), Kurz and Schneider (1996), Kurz and Beltratti (1997), Kurz and Motolese (2001) and Nielsen (1996)). These papers aimed to explain a list of financial "anomalies." (for a unified treatment see Kurz and Motolese (2001)). The RBE theory was used by Kurz (1997b) and Nielsen (2003) to explain the volatility of foreign exchange rates. All these papers used OLG models in which exogenous shocks are discrete random variables and agents have a finite set of states of belief. Wu and Guo (2003) (2004) study speculation and trading volume in the steady state of an infinite horizon model. The novel contribution of this paper consists of three parts: (i) ours is a full infinite horizon model, (ii) all random variables are continuous and we use standard AR processes to describe beliefs and exogenous shocks, and (iii) we explicitly model agents' beliefs about the market state of belief, which amounts to beliefs about the beliefs of others. We argue that this mechanism is central to understanding the volatility and risk premia in financial markets.

\section{The Main Findings}

In this paper we show that there are two simple characteristics of diverse market beliefs which fully account for the characteristics of market volatility and premia observed in real markets:

(A) high intensity of fat tails in the belief densities of agents;

(B) asymmetry in the proportion of bull and bear states in the market over time.

High intensity means the subjective densities agents use to make forecasts have fat tails, the sizes of which depend upon their states of belief. Asymmetry in the time frequency of belief states is a subtle characteristic which says that on average, agents are in bear states at more than $50 \%$ of the dates. Equivalently, on average, at more than half of the time agents do not expect to make above normal return on their investments. Therefore, it follows from the RB principle that when agents are in bull states and expect above normal returns, their expected excess returns tend to be very high. This asymmetry reflects the fact that major rises in stock prices occur over a relatively small fraction of 
time following market declines. Hence, when agents are in states where they believe a bull market is ahead, they also expect to make large excess return over relatively shorter periods.

The same model we use to study the statistics of market volatility is used to study other aspects of market dynamics. We show that our model implies market returns must exhibit stochastic volatility which is generated by the dynamics of the market state of belief. In addition, stock prices and returns exhibit a structure of forecastability which is observed in the real data.

We formulate a general equilibrium, consumption based, asset pricing model and study its computational solutions. However, the paper is not intended as calibration work. Although our numerical results correspond well to the observed market data, the numerical results are used merely to draw theoretical conclusions by highlighting the qualitative implications of our theory.

As to organization, in Section 1 we formulate a model with two infinitely lived dynasties of agents and two assets. In section 2 we study the volatility of the corresponding REE. In section 3 we define the RBE, explain the rationality of belief conditions and the restrictions they impose on beliefs. In Section 4 we study moments implied by the RBE. In Section 5 we study the stochastic volatility implied by the RBE and in Section 6 we take up the predictability of returns.

\section{The Economic Environment}

The model economy has two types of agents and a large number of identical agents within each type. Each agent is a member of one of two types of infinitely lived dynasties identified by their endowment, their utility which is defined over consumption and by their belief. A member of a dynasty lives a fixed short life and during his life makes decisions based on his own state of belief without knowing the states of belief of his predecessors. There are two traded assets: a stock and a riskless, one period, bond. The economy has an aggregate output process $\left\{Y_{t}, t=1,2, \ldots\right\}$ which is divided between dividends $\left\{D_{t}, t=1,2, \ldots\right\}$ paid to owners of the common stock and non dividend endowment which is paid to the agents. The dividend process is described by

$$
\mathrm{D}_{\mathrm{t}+1}=\mathrm{D}_{\mathrm{t}} \mathrm{e}^{\mathrm{x}_{\mathrm{t}+1}}
$$

where $\left\{\mathrm{x}_{\mathrm{t}}, \mathrm{t}=1,2, \ldots\right\}$ is a stochastic process under a true probability which is non-stationary with structural breaks and time dependent distribution. We assume the growth process is a stable 
process ${ }^{5}$ hence it has an empirical distribution which the agents learn and know. This empirical distribution is represented by the growth rate being a stationary Markov process defined by ${ }^{6}$

$$
\mathrm{x}_{\mathrm{t}+1}=\left(1-\lambda_{\mathrm{x}}\right) \mathrm{x}^{*}+\lambda_{\mathrm{x}} \mathrm{x}_{\mathrm{t}}+\rho_{\mathrm{t}+1}^{\mathrm{x}} \quad \text { with } \quad \rho_{\mathrm{t}+1}^{\mathrm{x}} \sim \mathrm{N}\left(0, \sigma_{\mathrm{x}}^{2}\right) \text { i.i.d. }
$$

The infinitely lived agents are enumerated $j=1,2$ and we use the following notation:

$\mathrm{C}_{\mathrm{t}}^{\mathrm{j}}$ - consumption of $\mathrm{j}$ at $\mathrm{t}$;

$\theta_{t}^{j}-$ amount of stock purchased by $j$ at $t$;

$\mathrm{B}_{\mathrm{t}}^{\mathrm{j}}$ - amount of one period bond purchased at discount by agent $\mathrm{j}$ at $\mathrm{t}$;

$\tilde{\mathrm{q}}_{\mathrm{t}}^{\mathrm{s}}$ - stock price at date $\mathrm{t}$;

$\mathrm{q}_{\mathrm{t}}^{\mathrm{b}}$ - the discount price of a one period bond at $\mathrm{t}$;

$\Lambda_{\mathrm{t}}^{\mathrm{j}}$ - non capital income of agent $\mathrm{j}$ at date $\mathrm{t}$;

$\mathrm{H}_{\mathrm{t}}$ - information at $\mathrm{t}$, recording the history of all observables up to $\mathrm{t}$.

Given probability belief $Q_{t}^{j}$, agent $j$ selects portfolio and consumption plans to solve the problem

subject to:

$$
\underset{\left(C^{j}, \theta^{j}, B^{j}\right)}{\operatorname{Max}} E_{Q^{j}}\left[\sum_{t=0}^{\infty} \beta^{t} \frac{1}{1-\gamma}\left(C_{t}^{j}\right)^{1-\gamma} \mid H_{t}\right]
$$

$$
C_{t}^{j}+\tilde{q}_{t}^{s} \theta_{t}^{j}+q_{t}^{b} B_{t}^{j}=\Lambda_{t}^{j}+\left(\tilde{q}_{t}^{s}+D_{t}\right) \theta_{t-1}^{j}+B_{t-1}^{j}
$$

We assume additively separable, power utility over consumption, a model that failed to generate premia in other studies (see, Campbell and Cochrane (2000)). We focus on diverse beliefs hence assume the two utility functions are the same. Introduce the normalization for $\mathrm{j}=1,2$

\footnotetext{
${ }^{5}$ A Stable Process is defined in Kurz (1994). It is a stochastic process which has an empirical distribution of the observable variables defined by the limits of relative frequencies of finite dimensional events. These limits are used to define the empirical distribution which, in turn, induces a probability measure over infinite sequences of observables which is central to the theory of Rational Beliefs.

${ }^{6}$ The key assumption is then that agents do not know the true probability but have ample past data from which they deduce that (2) is implied by the empirical distribution. Hence the data reveals a memory of length 1 and residuals which are i.i.d. normal. This assumption means that even if (2) is the true data generating process, agents do not know this fact. An agent who holds a Rational Belief may believe the true process is non-stationary and different from (2), but to be rational his model is required to generates the same statistics (i.e. empirical distribution) as generated by (2).
} 


$$
\omega_{t}^{j} \equiv \frac{\Lambda_{t}^{j}}{D_{t}} \quad, \quad c_{t}^{j} \equiv \frac{C_{t}^{j}}{D_{t}} \quad, \quad q_{t}{ }^{s} \equiv \frac{\tilde{q}_{t}^{s}}{D_{t}} \quad, \quad b_{t}^{j} \equiv \frac{B_{t}{ }^{j}}{D_{t}} .
$$

With this normalization the budget constraint becomes

$$
c_{t}^{j}+q_{t}^{s} \theta_{t}^{j}+q_{t} b_{t} b^{j}=\omega_{t}^{j}+\left(q_{t}^{s}+1\right) \theta_{t-1}^{j}+b_{t-1}^{j} e^{-x_{t}} .
$$

The Euler equations are

$$
\begin{aligned}
& \left(c_{t}^{j}\right)^{-\gamma} q_{t}{ }^{s}=\beta E_{Q_{t}^{j}}\left[\left(c_{t+1}^{j}\right)^{-\gamma}\left(1+q_{t+1}^{s}\right) e^{(1-\gamma) x_{t+1}} \mid H_{t}\right] \\
& \left(c_{t}^{j}\right)^{-\gamma} q_{t}^{b}=\beta E_{Q_{t}^{j}}\left[\left(c_{t+1}^{j}\right)^{-\gamma} e^{-\gamma x_{t+1}} \mid H_{t}\right]
\end{aligned}
$$

and the market clearing conditions are then

$$
\begin{aligned}
& \theta_{\mathrm{t}}^{1}+\theta_{\mathrm{t}}^{2}=1 \\
& \mathrm{~b}_{\mathrm{t}}{ }^{1}+\mathrm{b}_{\mathrm{t}}{ }^{2}=0 .
\end{aligned}
$$

\section{A Rational Expectations Equilibrium (REE)}

To evaluate the volatility of an REE in an annual model we specify parameters of the growth process (2). Unfortunately, different estimates of the parameter values are available, depending upon time span of data, unit of time (annual vs. quarterly) and the definition of terms (see, for a sample, Backus, Gregory and Zin (1989), Campbell (2000) and Rodriguez (2002) Appendix 2, based on Shiller in (http://www.econ.yale.edu/shiller)). We use the annual estimates reported in Campbell (2000) Table 3, which are consistent with estimates of Mehra and Prescott (1984). For the rest of this paper we set $\beta=0.96, \gamma=2.00, x^{*}=0.01773, \lambda_{x}=-0.117$ and $\sigma_{x}=0.03256$, all well within the empirically estimated range. Ours is a theoretical paper aiming to draw qualitative conclusions. Still, we select realistic parameter values since we wish our simulations to result in numerical values as close to the observed data as possible. For simplicity we assume $\omega_{t}^{j}=\omega$, a constant. Total resources, or GNP, is equal to $(1+2 \omega) D_{t}$ hence the Dividend/GNP ratio is $\frac{1}{1+2 \omega}$. As we model only income from publically traded stock ownership, the ratio of Dividends to Household Income should include dividends of the corporate sector but exclude self employed income and imputed income from other asset categories. This ratio is about 15\% (see survey data in Heaton and Lucas (1996)) hence we select $\omega_{t}^{\mathrm{j}}=3$. This has little effect on the results.

We define the REE as a solution when agents believe (2) is the truth. We simulated this REE and report in Table 1the mean and standard deviations of (i) the priceldividend ratio $\mathrm{q}^{\mathrm{s}}$, (ii) the 
risky return $\mathrm{R}$ on the stock, (iii) the one year riskless interest rate $\mathrm{r}$, the premium $\mathrm{e}_{\mathrm{p}}$ of equity return over the return on one year bond, the Sharp Ratio and the correlation between $\mathrm{x}$ and stock returns. Moments of market data vary with sources reporting and methods of estimation. The estimates in Table 1 are based on Shiller (http://www.econ.yale.edu/shiller) and others. They represent our best approximation of the order of magnitude of the data reported in most studies.

Table 1: Simulated Moments Of Key Variables In REE (all moments are annualized)

\begin{tabular}{|l|c|c|c|c|c|c|c|c|c|}
\hline & $\mathrm{q}^{\mathrm{s}}$ & $\sigma_{\mathrm{q}^{\mathrm{s}}}$ & $\mathrm{R}$ & $\sigma_{\mathrm{R}}$ & $\mathrm{r}$ & $\sigma_{\mathrm{r}}$ & $\mathrm{e}_{\mathrm{p}}$ & shrp & $\rho_{\mathrm{Rx}}$ \\
\hline Model Data & 16.71 & 0.055 & $7.94 \%$ & $3.78 \%$ & $7.70 \%$ & $0.79 \%$ & $0.24 \%$ & 0.064 & .995 \\
\hline Market Data & 25 & 7.1 & $7 \%$ & $18.00 \%$ & $1.00 \%$ & $5.70 \%$ & $6.00 \%$ & $1 / 3$ & .100 \\
\hline
\end{tabular}

The results in Table 1 are familiar. Note that apart from the low equity premium, the volatility of the REE in Table 1 is low: all model volatility measures are lower than market data by an order of magnitude. The debate about these results under the heading of the "Equity Premium Puzzle" is important since the asset pricing theory is derived in a general equilibrium framework. Hence the puzzle requires us to reevaluate the economic foundations of the REE paradigm.

Some writers argued in favor of introducing habit formation in utility to generate time variability of risk aversion (e.g. see Abel (1990), (1999), and Constantinides (1990) ${ }^{8}$ ). Campbell and Cochrane (1999), (2000) assume that at habit the marginal utility of consumption and degree of risk aversion rise without bound. Hence, when consumption declines to habit risk aversion increases, stock prices decline and risk premium rises. Although the model generates moments which are closer to those observed in the market, the theory is unsatisfactory. First, with $\mathrm{X}_{\mathrm{t}}=$ habit, utility is $\frac{1}{1-\gamma}\left(\mathrm{C}_{\mathrm{t}}-\mathrm{X}_{\mathrm{t}}\right)^{1-\gamma}$. But why should the marginal utility and risk aversion explode when $\mathrm{C}_{\mathrm{t}}$ approaches the mean of past consumption? Campbell and Cochrane (1999, page 244) show that for the model to generate the desired moments, the degree of risk aversion is 80 at steady state and exceeds 300 frequently along any time path. If instead we use Abel's (1990), (1999) formulation

${ }^{8}$ Other approaches to the equity premium puzzle were reported by Brennan and Xia [1998], Epstein and Zin [1990], Cecchetti, Lam and Mark [1990],[1993], Heaton and Lucas [1996], Mankiw [1986], Reitz [1988], Weil [1989] and others. For more details see Kocherlakota [1996]. Some degree of excess volatility can also be explained with explicit learning mechanism which does not die out (see for example Timmermann (1996)). 
$\frac{1}{1-\gamma}\left(\frac{C_{t}}{X_{t}}\right)^{1-\gamma}$, marginal utility is normalized to be 1 at habit but the model does not generate volatility. Second, big fluctuations of stock prices are observed during long periods when consumption grows smoothly as was the case during the volatile period of 1992 - 2002. Finally, the model predicts perfect correlation between consumption growth and stock returns but the record (see Table 1) shows date $\mathrm{t}$ stock returns have low correlation with date $\mathrm{t}$ consumption growth. Above all, the habit formation model proposes a theory which claims that asset premia are caused by an unreasonably high degree of risk aversion. Our alternative view proposes that risk premia are determined primarily by the structure of market expectations.

\section{Constructing a Rational Belief Equilibrium (RBE)}

\section{$3.1 \quad$ States of Belief and RBE}

In a typical RBE agents believe the environment is not stationary and past data do not provide a perfect guide to the future. As a result, a given stochastic process of exogenous shocks is compatible with diverse beliefs about the future and hence with diverse RBE. Our methodology of studying RBE is to construct a large family of such equilibria and to examine the volatility characteristics of its members. The family is characterized by an AR stochastic law of motion of the state and by a structure of agents' beliefs. We think the structure of beliefs is as primitive an explanatory variable of economic phenomena as utility, technology or financial constraints. Hence we aim to understand the characteristics of those belief structures which generates volatility and premia in the order of magnitudes observed in the data.

To define RB, consider the economy as a data generating mechanism so that from past data agents know the empirical distribution of observables. A Rational Belief is a probability measure on sequences of future states together with a model of the economy. It has a property that if simulated, it generates the same empirical distribution as the empirical distribution of the observables in the real economy. Conditional forecasts induced by an RB may be wrong at any date but their time average are correct in the sense that they equal the forecasts that would be made with the probability measure implied by the empirical distribution. We call this probability The Stationary, or Empirical, 
Measure ${ }^{9}$. To use these ideas we need a tractable way to describe beliefs and this is our next task.

The tool we use to describe the distribution of beliefs at date t is the "market state of belief." In a two agent economy it is a vector $\mathrm{z}_{\mathrm{t}}=\left(\mathrm{z}_{\mathrm{t}}^{1}, \mathrm{z}_{\mathrm{t}}^{2}\right) \in \mathbb{R}^{2}$ which defines uniquely date $t$ conditional probability functions of the agents. In any equilibrium endogenous variables are functions of state variables, lagged endogenous variables and in our case we add $\left(\mathrm{z}_{\mathrm{t}}^{1}, \mathrm{z}_{\mathrm{t}}^{2}\right)$. If we denote exogenous shocks and lagged endogenous variables by $s_{t}$, the equilibrium price process $\left\{\left(q_{t}{ }^{s}, q_{t}{ }^{b}\right), t=1,2, \ldots\right\}$ is then defined by a map like

$$
\left[\begin{array}{c}
q_{t}^{s} \\
q_{t}^{b}
\end{array}\right]=\Xi\left(s_{t}, z_{t}^{1}, z_{t}^{2}\right)
$$

Our equilibrium is thus a Radner (1972) equilibrium with an expanded state space that includes state of belief $\left(\mathrm{z}_{\mathrm{t}}{ }^{1}, \mathrm{z}_{\mathrm{t}}{ }^{2}\right)$. The map (5) reflects this fact. Since agents use the price map (5) to forecast future prices, they need to forecast future market states of beliefs, which are the future beliefs of "other" agents. Although both agents use $\Xi$ in (5) to forecast $t+1$ prices, their price forecasts are different since each agent forecasts future state variables and future market beliefs given his private state of belief. We explore this issue later when we discuss the subjective models of the agents.

In this paper we construct an RBE, use perturbation methods to compute it and study its volatility via simulations. Since we wish to demonstrate our economy exhibits fluctuations which are qualitatively similar to those observed in the market, our construction proceeds in three steps ${ }^{10}$. (i) Specify a family of empirical distributions of state variables which is then assumed known to agents who learn it from the data. Most parameter values are based on their empirical estimates, known from other studies. Some values are based on our best judgement.

\footnotetext{
${ }^{9}$ The empirical distribution of the observable variables or their moments induce a probability measure over infinite sequences of observables which is central to the theory of Rational Beliefs. A general definition and construction of this probability measure is explained in Kurz (1994), (1997) or Kurz-Motolese (2001) where it is shown that this probability must be stationary. Statements in the text about "the stationary measure" or "the empirical distribution" is always a reference to this probability. Its centrality arises from the fact that it is derived from public information and hence the stationary measure is known to all agents and agreed upon by all to reflect the empirical distribution of observable equilibrium variables. In terms of equilibrium concepts, an RBE has the property that within the set of market beliefs an RBE is a fixed point in empirical distributions.

${ }^{10}$ For a detailed account of the theory of Rational Beliefs see Kurz (1997a) and for additional details regarding the constructive approach to RBE, see Kurz and Motolese (2001), Section 2.4.
} 
(ii) Specify the beliefs of agents and formulate conditions which then rationalize them relative to the empirical distribution specified in (i). These are the rationality conditions of the RBE.

(iii) Use the equilibrium conditions developed earlier to define equilibrium prices and endogenous variables, and then study the dynamics of an equilibrium by simulating the model economy.

\subsection{The Empirical Distribution of the State}

In a Markov economy a probability is represented by transition functions over states. In our constructed RBE the state vector is $\left(x_{t}, z_{t}^{1}, z_{t}^{2}\right)$ where $x_{t}$ is the growth rate of dividends and $\left(z_{t}^{1}, z_{t}^{2}\right)$ is the market state of belief. In a large economy it would be a distribution but here we have only two dynasties. For an empirical distribution we specify stationary transition functions for the state variables. The true process of the shocks $\left\{x_{t}, t=1,2, \ldots\right\}$ is a stable and non-stationary process, incorporating structural changes, with a probability law which is not known to the agents. However, for equilibrium analysis the true process does not matter: all that matters is the empirical distribution of the process and what agents believe about the true process. We assume the joint empirical distribution of the exogenous shocks and the states of belief is an AR process of the form

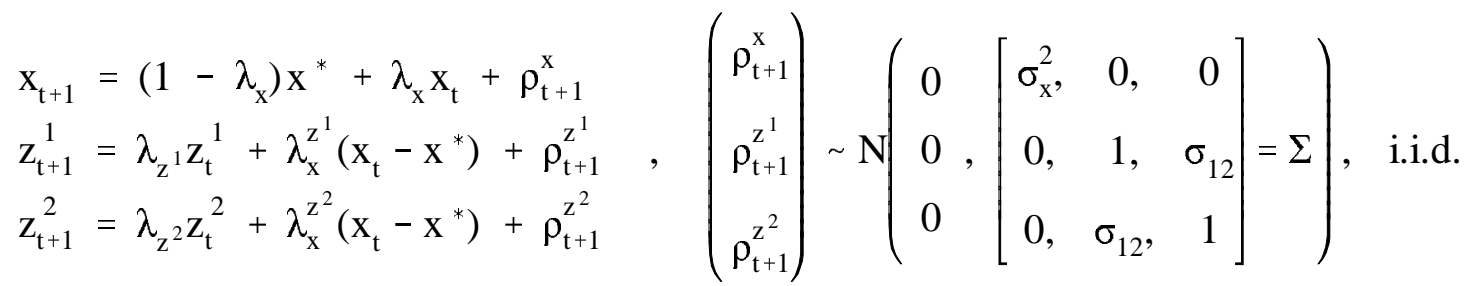

Values for $\left(\lambda_{\mathrm{x}}, \mathrm{x}^{*}, \sigma_{\mathrm{x}}\right)$ were set in Section 2. We normalize by setting variances of $\rho_{\mathrm{t}+1}^{\mathrm{z}^{\mathrm{j}}}$ equal to 1 . To specify parameters of the $\mathrm{z}^{\mathrm{j}}$ equations we explain later the index $\mathrm{z}^{\mathrm{j}}$ measures how optimistic an agent is about future returns on investment. With this in mind we used forecasts reported by the Blue Chip Economic Indicators and the Survey of Professional Forecasters, and "purged" them of observables. We then estimated principal components to handle multitude of forecasted variables (for details, see Fan (2003)). The extracted indexes of beliefs imply regression coefficients around $0.5-0.8$ hence we set $\lambda_{\mathrm{z}^{1}}=\lambda_{\mathrm{z}^{2}}=0.7$. There is high correlation across investors who forecast financial variables such as corporate profits. Even higher correlation exists with respect to forecasts of productivity growth. We thus set $\sigma_{z^{1} z^{2}}=0.90$. In this paper we study only symmetric 
economies where agents differ only in their beliefs hence we assume $\lambda_{x}^{z^{1}}=\lambda_{x}^{z^{2}}=\lambda_{x}^{z}$. The evidence shows that positive productivity shocks lead agents to revise upward their economic growth forecasts implying $\lambda_{x}^{z}>0$. Our best guess of this parameter leads us to set $\lambda_{x}^{z}=2.0$ but we discuss it again later. Finally, we denote by $\mathrm{m}$ the probability measure on infinite sequences implied by (6) together with the invariant distribution as the initial distribution.

To write (6) in a more compact notation let $\mathrm{w}_{\mathrm{t}}=\left(\mathrm{x}_{\mathrm{t}}-\mathrm{x}^{*}, \mathrm{z}_{\mathrm{t}}^{1}, \mathrm{z}_{\mathrm{t}}^{2}\right), \rho_{\mathrm{t}}=\left(\rho_{\mathrm{t}}^{\mathrm{x}}, \rho_{\mathrm{t}}^{\mathrm{z}^{1}}, \rho_{\mathrm{t}}^{\mathrm{z}^{2}}\right)$ and denote by $\mathrm{A}$ the $3 \times 3$ matrix of parameters in (6). We then write (6a) - (6c) as

$$
\mathrm{w}_{\mathrm{t}+1}=\mathrm{Aw}_{\mathrm{t}}+\rho_{\mathrm{t}+1} \quad, \quad \rho_{\mathrm{t}+1} \sim \mathrm{N}(0, \Sigma)
$$

where $\Sigma$ is the covariance matrix in (6). Denote by V the $3 \times 3$ unconditional covariance of w defined by $\mathrm{V}=\mathrm{E}_{\mathrm{m}}\left(\mathrm{Ww}^{\prime}\right)$. We later need the value of $\mathrm{V}$ and compute it as solution of the equation

$$
\mathrm{V}=\mathrm{AVA}^{\prime}+\Sigma
$$

\subsection{Personal States of Belief and the Anonymity Principle}

In a non-stationary environment, an agent's conditional probability is time dependent and over time he deviates from the forecasts implied by the empirical distribution. His conditional probability may be above the empirical probability (he is "optimistic") or below it (he is "pessimistic"). But why specify the formal belief formation model our agent uses to deviate from the stationary empirical forecasts? A theory that uses the distribution of heterogenous beliefs to explain observed phenomena faces the problem of determining a level of detail at which agents explain why they adopt the beliefs they hold. If we require a complete specification of such modeling, a theory is doomed to get bogged down in details about inference from small samples and information processing. Such approach is useful, but from the perspective of equilibrium theory it is not needed. All we need is a method to describe how an agent's model affects his conditional probability and to ensure the rationality of belief conditions are satisfied. Since the rationality principle requires the time average of the conditional probabilities to equal the empirical frequency, his conditional probability beliefs fluctuate around the empirical measure. Hence we seek a tractable 
mathematical description of non-stationarity with which to keep track of the statistical regularity at which an agent deviates from stationary forecasts.

Our tool to accomplish the above goals is the state of belief $\mathrm{y}_{\mathrm{t}}^{\mathrm{j}} \varepsilon \mathrm{Y}^{\mathrm{j}}$ of $\mathrm{j}$. It is an index which fully specifies his conditional probability function. ${ }^{11}$ It is formally similar to models where $\mathrm{Y}$ is a set of possible regimes, and $y_{t}$ are "regime variables." The subjective variables $y_{t}{ }^{j} \varepsilon Y^{j}$ are parameters the agent uses to describe his belief. Their main benefit is statistical since the stochastic structure specifies the empirical regularity of $y_{t}{ }^{j}$ and this regularity is used to state the rationality of belief conditions. Since rational agents do not deviate systematically from empirical forecasts, in order to establish rationality of belief we need a statistical measure of an agent's deviations from these forecasts. $\mathrm{y}_{\mathrm{t}}{ }^{\mathrm{j}} \varepsilon \mathrm{Y}^{\mathrm{j}}$ are simple mathematical devices used to measure such regularity.

We remark that $\mathrm{y}_{\mathrm{t}}^{\mathrm{j}}$ are privately perceived by agent $\mathrm{j}$ and have meaning only to him. Since a dynasty consists of a sequence of decision makers, $y_{t}{ }^{j}$ used by one has no bearing on the description of beliefs by other dynasty members. $\mathrm{Y}^{\mathrm{j}}$ and $\mathrm{Y}^{\mathrm{k}}$ for $\mathrm{j} \neq \mathrm{k}$ do not even need to be the same spaces: an agent's theory about investing in technology of one era (when $\mathrm{j}$ lives) has nothing to do with the reality of investments at a different era (when $\mathrm{k}$ lives). Unfortunately, diversity of $\mathrm{Y}^{\mathrm{j}} \neq \mathrm{Y}^{\mathrm{k}}$ for $\mathrm{j} \neq \mathrm{k}$ is not tractable. To improve tractability we make two assumptions. First, we use the same space $\mathrm{Y}^{\mathrm{j}}=\mathbb{R}$ for all $\mathrm{j}$ and assume an agent knows only the short history of his own $\mathrm{y}_{\mathrm{t}}^{\mathrm{j}}$. He does not know the states of belief of his predecessors. Second, we assume individual states are made public and their distribution $\left(\mathrm{z}_{\mathrm{t}}{ }^{1}, \mathrm{z}_{\mathrm{t}}^{2}\right)$ is recorded as a "market state of beliefs" subject to the anonymity of individuals behind public data. To maintain competitiveness, each agent is assumed not to associate his own belief with market states. Due to the fact that there are two types of agents this anonymity assumption needs clarification.

Although the market state of beliefs at $t$ is nothing but a distribution of the $y_{t}{ }^{j}$, anonymity

\footnotetext{
${ }^{11}$ Thus let $\mathrm{X}$ be a space of observables and let $\left((\mathrm{X})^{\infty}, \mathscr{B}(\mathrm{X})^{\infty}\right)$ be the space of infinite sequences of observables where $\mathscr{B}\left((\mathrm{X})^{\infty}\right)$ is the Borel $\sigma$-field of $(\mathrm{X})^{\infty}$. To describe a non-stationary process we use variables $\mathrm{y}_{\mathrm{t}}^{\mathrm{j}} \varepsilon \mathrm{Y}^{\mathrm{j}}$ with a marginal probability space $\left(\left(\mathrm{Y}^{\mathrm{j}}\right)^{\infty}, \mathcal{O}\left(\left(\mathrm{Y}^{\mathrm{j}}\right)^{\infty}, \mu\right)\right.$. We then define the desired non-stationary probability to be $\mathrm{Q}_{\mathrm{y}}^{\mathrm{j}} \equiv \mathrm{Q}^{\mathrm{j}}\left((\bullet) \mid \mathrm{y}^{\mathrm{j}}\right)$, the conditional probability of $\mathrm{Q}^{\mathrm{j}}$ with respect to the sequence $\mathrm{y}^{\mathrm{j}}$. $\mathrm{Q}^{\mathrm{j}}$ satisfies the condition that for all $\mathrm{A} \varepsilon \mathscr{B}\left(\mathrm{X}^{\circ}\right)$ and $\mathrm{B} \varepsilon \mathscr{B}\left(\left(\mathrm{Y}^{\mathrm{j}}\right)^{\infty}\right)$

$$
Q^{j}(A \times B)=\int_{B} Q_{y}^{j}(A) \mu\left(d y{ }^{j}\right) .
$$

The effective probability space $\left((\mathrm{X})^{\infty}, O\left((\mathrm{X})^{\infty}, \mathrm{Q}_{\mathrm{y}}{ }_{\mathrm{j}}^{\mathrm{j}}\right)\right.$ implies non-stationary dynamics of the observables since probabilities of events in $\mathscr{B}\left((\mathrm{X})^{\infty}\right)$ are not time invariant: they change with the time varying parameters $\mathrm{y}_{\mathrm{t}}{ }^{\mathrm{j}}$.
} 
requires that agents do not make any connection between their own $y_{t}{ }^{j}$ and the distribution of beliefs in the market ${ }^{12}$. Anonymity is so central that we use three notational devices to highlight it.

(i) $\mathrm{y}_{\mathrm{t}}^{\mathrm{j}}$ denotes the state of belief of $\mathrm{j}$ as known by the agent only.

(ii) $\left(\mathrm{z}_{\mathrm{t}}{ }^{1}, \mathrm{z}_{\mathrm{t}}^{2}\right)$ denotes the market state of belief, observed by all agents. Being competitive, they do not associate $\mathrm{y}_{\mathrm{t}}^{\mathrm{j}}$ with $\left(\mathrm{z}_{\mathrm{t}}^{1}, \mathrm{z}_{\mathrm{t}}^{2}\right)$ although $\mathrm{y}_{\mathrm{t}}{ }^{\mathrm{j}}=\mathrm{z}_{\mathrm{t}}^{\mathrm{j}}$ is a basic consistency condition.

(iii) $\left(\mathrm{z}_{\mathrm{t}+1}^{\mathrm{j} 1}, \mathrm{z}_{\mathrm{t}+1}^{\mathrm{j} 2}\right)$ describes agent $\mathrm{j}$ 's forecast of the market state of belief at future date $\mathrm{t}+1$. To state the rationality of belief conditions we specify a sequence of individual states $\left\{y_{t}^{j}, t=1,2\right.$, ... f for $\mathrm{j}=1,2$. The consistency condition $\mathrm{y}_{\mathrm{t}}^{\mathrm{j}}=\mathrm{z}_{\mathrm{t}}^{\mathrm{j}}$ requires the empirical distribution of $\mathrm{y}_{\mathrm{t}}^{\mathrm{j}}$ to be the same as the distribution of $z_{t}^{j}$ in (6). Thus, the agent's state of belief is characterized by a sequence of random variables $\tilde{\rho}_{t}^{y^{j}}, t=1,2, \ldots$ such that $\left\{y_{t}^{j}, t=1,2, \ldots\right\}$ are the realizations of

$$
\mathrm{y}_{\mathrm{t}+1}^{\mathrm{j}}=\lambda_{\mathrm{z}} \mathrm{y}_{\mathrm{t}}^{\mathrm{j}}+\lambda_{\mathrm{x}}^{\mathrm{z}^{\mathrm{j}}}\left(\mathrm{x}_{\mathrm{t}}-\mathrm{x}^{*}\right)+\tilde{\rho}_{\mathrm{t}+1}^{\mathrm{y}^{\mathrm{j}}} \quad, \quad \tilde{\rho}_{\mathrm{t}+1}^{\mathrm{y}^{\mathrm{j}}} \sim \mathrm{N}\left(0, \tilde{\sigma}_{\mathrm{y}}^{2}\right) \quad, \quad \mathrm{j}=1,2 .
$$

(9) is compatible with the $z_{t}^{j}$ equation in (6) except that (6) specifies a joint distribution of all state variables while (9) specifies only a marginal distribution of $\mathrm{j}$ as perceived by agent $\mathrm{j}$ (for more details, see Appendix B). Since $\left\{\mathrm{y}_{\mathrm{t}}^{\mathrm{j}}, \mathrm{t}=1,2, \ldots\right\}$ exhibit serial correlation, we exclude from $\mathrm{y}_{\mathrm{t}}{ }^{\mathrm{j}}$ all information already in the market at $\mathrm{t}$ in order to isolate the pure subjective component of belief. To that end introduce a variable $u_{t}{ }^{j}\left(y_{t}^{j}\right)$ as follows. Denote by $r_{j}=\operatorname{Cov}\left(w, y^{j}\right)$ agent $j$ 's covariance vector and, keeping in mind (8), define $\mathrm{u}_{\mathrm{t}}{ }^{\mathrm{j}}\left(\mathrm{y}_{\mathrm{t}}^{\mathrm{j}}\right)$ by the following regression filter

$$
u_{t}^{j}\left(y_{t}^{j}\right)=y_{t}^{j}-r_{j}^{\prime} V^{-1} w_{t}
$$

By construction, the pure belief $\mathrm{u}_{\mathrm{t}}^{\mathrm{j}}\left(\mathrm{y}_{\mathrm{t}}^{\mathrm{j}}\right)$ is uncorrelated with date $\mathrm{t}$ public information. We show later that it is serially uncorrelated. Note that $u_{t}{ }^{j}\left(y_{t}{ }^{j}\right)$ acquires meaning only when we specify what $j$ does in state $y_{t}{ }^{j}$. The formal structure to do that are the perception models of the agents.

${ }^{12}$ This requirement on the agent is analogous to the behavior of producers in a competitive market with a finite number of firms who are required to disregard their impact on prices. By looking at past data a competitive firm in a market with a finite number of firms can demonstrate that it had an effect on prices in violation of this assumption. This type of empirical "test" is what is assumed away here to ensure competitive behavior of agents. 


\subsection{Perception Models and the Rationality of Belief Conditions}

A perception model is a set of transition functions of the state variables, reflecting the agent's belief about date $t+1$ transition probability. We first explain the general form of a perception model, using (7), providing details later. Let $\mathrm{w}_{\mathrm{t}+1}^{\mathrm{j}}$ be a vector of state variables at date $\mathrm{t}+1$ as perceived by agent $j$ and let $\Psi_{\mathrm{t}+1}\left(\mathrm{u}_{\mathrm{t}}{ }^{\mathrm{j}}\right)$ be a 3 dimensional vector of date $\mathrm{t}+1$ random variables conditional upon parameter $y_{t}^{j}$. A perception model has then the general form

$$
\mathrm{w}_{\mathrm{t}+1}^{\mathrm{j}}=A \mathrm{w}_{\mathrm{t}}+\Psi_{\mathrm{t}+1}\left(\mathrm{u}_{\mathrm{t}}^{\mathrm{j}}\right) \text { together with (9). }
$$

Since $E_{m}\left(w_{t+1} \mid H_{t}\right)=A w_{t}$ write (11a) in the simpler form

$$
\mathrm{w}_{\mathrm{t}+1}^{\mathrm{j}}-\mathrm{E}_{\mathrm{m}}\left(\mathrm{w}_{\mathrm{t}+1} \mid \mathrm{H}_{\mathrm{t}}\right)=\Psi_{\mathrm{t}+1}\left(\mathrm{u}_{\mathrm{t}}^{\mathrm{j}}\right) \text {. }
$$

In general $\mathrm{E}\left[\Psi_{\mathrm{t}+1} \mid \mathrm{u}_{\mathrm{t}}{ }_{\mathrm{j}}\right] \neq 0$ hence the mean value of the agent's forecast changes with the state of belief . (11a) -(11b) show how agent j's expectations deviate from $E_{m}\left(w_{t+1} \mid H_{t}\right)$ and how the deviations depends upon $y_{t}^{j}$ via $u_{t}^{j}$. If $\Psi_{t+1}\left(u_{t}^{j}\right)=\rho_{t+1}$ as in (7), $j$ uses the empirical probability $\mathrm{m}$ as his belief. With this formulation we can state the rationality of belief conditions. These require the empirical distributions of (7) and (11a) to be the same. For $w_{t+1}-E_{m}\left(w_{t+1} \mid H_{t}\right)$ to have the same empirical distribution as $\mathrm{w}_{\mathrm{t}+1}^{\mathrm{j}}-\mathrm{E}_{\mathrm{m}}\left(\mathrm{w}_{\mathrm{t}+1} \mid \mathrm{H}_{\mathrm{t}}\right)$ means that the empirical distribution of $\left.\left\{\Psi_{\mathrm{t}+1}\left(\mathrm{u}_{\mathrm{t}}^{\mathrm{j}}\right), \mathrm{t}=1,2, \ldots\right)\right\}$ in (11a) is the same as the distribution of $\rho_{\mathrm{t}+1}$ in (7), which is $\mathrm{N}(0, \Sigma)$. This implies the empirical distribution of $\left.\left\{\Psi_{\mathrm{t}+1}\left(\mathrm{u}_{\mathrm{t}}^{\mathrm{j}}\right), \mathrm{t}=1,2, \ldots\right)\right\}$ is $\mathrm{N}(0, \Sigma)^{13}$ and $\Psi_{\mathrm{t}+1}\left(\mathrm{u}_{\mathrm{t}}^{\mathrm{j}}\right)$ does not exhibit serial correlation. We now explain the details of these requirements.

\section{4a Formulating The Perception Models}

In modeling $\Psi_{\mathrm{t}+1}\left(\mathrm{u}_{\mathrm{t}}{ }^{\mathrm{j}}\right)$ we consider several factors. Agents may be over confident by being optimistic or pessimistic relative to the empirical forecasts. Evidence from the psychological literature (e.g. Svenson (1981), Camerer and Lovallo (1999) and references there) shows agents

${ }^{13}$ From the perspective of the agent the sequence $y_{t}{ }^{j}$ is just a sequence of parameters. However, for these rationality conditions we need to study the empirical distribution of sequences $\left.\left\{\Psi_{t+1}\left(u_{t}{ }^{j}\right), t=1,2, \ldots\right)\right\}$ which depend upon the $u_{t}{ }^{j}$. In order to do that we need to know the empirical regularity of the $y_{t}^{j}$ and this is where the specification (9), about the statistical regularity of these assessment variables, come into play. 
exhibit such behavior. Since in an RBE agents do not know the true probability, in our context such behavior is not irrational if it respects the rationality principle. But why do agents make either bullish or bearish forecasts in our model? Condition (6) specifies only the empirical distribution of a non-stationary state process. Moreover, for stating the Euler equations and equilibrium map the true process is not relevant; all that matters is what agents believe the process is. Technological and institutional changes are central features of our economy and past statistics do not provide the best forecasts for the future. Deviations from the empirical forecast reflect judgements, based on limited recent data, about "structural breaks" or, more generally, about market "timing" and about changes in market conditions an agent believes are occurring. The motive for making such judgments arises from the substantial financial gains to agents who assess correctly the conditions which determine future dividends and prices. However, the formal subjective beliefformation modeling is kept in the background. A second factor to be considered in modeling $\Psi_{\mathrm{t}+1}\left(\mathrm{u}_{\mathrm{t}}{ }^{\mathrm{j}}\right)$ is related to the rationality conditions which require that $\Psi_{t+1}\left(u_{t}^{j}\right)$ is serially uncorrelated. Finally, the effect of the state of belief $u_{t}{ }^{j}$ on the forecast of agents has two different components which are operative in an RBE:

(i) frequency at which $\mathrm{u}_{\mathrm{t}}^{\mathrm{j}}$ induces deviations from the stationary forecast in each direction;

(ii) intensity of forecast deviation generated by any given value of $\mathrm{u}_{\mathrm{t}}{ }^{\mathrm{j}}$.

Rationality of belief implies a tradeoff between these two effects and this substitution is important and will be explored later when we discuss the results.

To address all these issues we specify the random sequence $\Psi_{t+1}\left(\mathrm{u}_{\mathrm{t}}^{\mathrm{j}}\right)$ to take the form

$$
\Psi_{t+1}\left(u_{t}^{j}\right)=\left(\begin{array}{l}
\lambda_{y}^{x} \rho_{t+1}^{j}\left(u_{t}^{j}\right)+\tilde{\rho}_{t+1}^{x} \\
\lambda_{y}^{z^{1}} \rho_{t+1}^{j}\left(u_{t}^{j}\right)+\tilde{\rho}_{t+1}^{z^{j 1}} \\
\lambda_{y}^{z^{2}} \rho_{t+1}^{j}\left(u_{t}^{j}\right)+\tilde{\rho}_{t+1}^{z^{j 2}}
\end{array}\right) .
$$

$\tilde{\rho}_{(t+1)}^{j}=\left(\tilde{\rho}_{t+1}^{\mathrm{x}}, \tilde{\rho}_{t+1}^{z^{j 1}}, \tilde{\rho}_{t+1}^{z^{j 2}}\right)$ are i.i.d. zero mean Normal variables with covariance matrix $\Omega_{\rho \rho}$ which is pinned down by the rationality conditions. $\Omega_{\rho \rho}$ is a $3 \times 3$ matrix, the same as $\Sigma$ in (7). But a perception model has $y_{t}{ }^{j}$ as a fourth dimension with a covariance matrix denoted by $\Omega$, reflecting the vector $r_{j}=\operatorname{Cov}\left(w, y^{j}\right)$ for $j=1,2$. The parameters $\lambda_{y}=\left(\lambda_{y^{1}}^{x}, \lambda_{y_{1}}^{z^{1}}, \lambda_{y_{1}}^{z^{2}}\right)=\left(\lambda_{y^{2}}^{x}, \lambda_{y^{2}}^{z^{1}}, \lambda_{y^{2}}^{z^{2}}\right)$ (equality due to symmetry) are the object of our study and their effect on volatility is examined later. We next construct the random variables $\rho_{t+1}^{j}\left(u_{t}^{j}\right)$. 
Asymmetry and Intensity of fat tails in the Random Variables $\Psi_{t+1}^{j}$

$\rho_{t+1}^{j}\left(u_{t}^{j}\right)$ allow belief to exhibit asymmetry and "fat" tails, reflecting over confidence. We define $\rho_{t+1}^{j}\left(u_{t}{ }^{j}\right)$ by specifying its density, conditional on $u_{t}{ }^{j}$ as a step function of the form

$$
P\left(\rho_{t+1}^{j} \mid u^{j}\right)= \begin{cases}\varphi_{1}\left(u^{j}\right) \Phi\left(\rho_{t+1}^{j}\right) & \text { if } \rho_{t+1}^{j} \geq 0 \\ \varphi_{2}\left(u^{j}\right) \Phi\left(\rho_{t+1}^{j}\right) & \text { if } \rho_{t+1}^{j}<0\end{cases}
$$

where $\rho_{\mathrm{t}+1}^{\mathrm{j}}$ and $\tilde{\rho}_{\mathrm{t}+1}^{\mathrm{y}^{\mathrm{j}}}($ in $(9))$ are independent and where $\Phi(\rho)=[1 / \sqrt{2 \pi}] \mathrm{e}^{-\frac{\rho^{2}}{2}}$. The functions $\left(\varphi_{1}(\mathrm{u}), \varphi_{2}(\mathrm{u})\right)$ are defined by a logistic function with two parameters $\mathrm{a}$ and $\mathrm{b}$

$$
\begin{gathered}
\varphi\left(\mathrm{u}^{\mathrm{j}}\right)=\frac{1}{1+\mathrm{e}^{\mathrm{b}\left(\mathrm{u}^{\mathrm{j}}-\mathrm{a}\right)}} \quad, \text { and define } \mathrm{G} \equiv \mathrm{E} \phi\left(\mathrm{u}^{\mathrm{j}}\right), \\
\mathrm{a}>0, \quad \mathrm{~b}>0 \text { and } \varphi_{2}\left(\mathrm{u}^{\mathrm{j}}\right)=\frac{\varphi\left(\mathrm{u}^{\mathrm{j}}\right)}{\mathrm{G}}, \varphi_{1}\left(\mathrm{u}^{\mathrm{j}}\right)=2-\varphi_{2}\left(\mathrm{u}^{\mathrm{j}}\right) .
\end{gathered}
$$

The parameter a measures asymmetry and the parameter b measures intensity of fat tails in beliefs. Technical details of this construction are discussed in Appendix A.

To explain (12)-(14), note that for $\mathrm{u}_{\mathrm{t}}^{\mathrm{j}}$ large, $\varphi\left(\mathrm{u}^{\mathrm{j}}\right)$ goes to zero, implying that $\varphi_{2}\left(\mathrm{u}^{\mathrm{j}}\right)$ goes to zero. Hence, by (12b) large $u_{t}^{j}>a$ implies high probability that $\rho_{t+1}^{j}>0$. Similarly, small $\mathrm{u}_{\mathrm{t}}{ }^{\mathrm{j}}<\mathrm{a}$ implies high probability that $\rho_{\mathrm{t}+1}^{\mathrm{j}}<0$. To interpret what $\mathrm{u}_{\mathrm{t}}{ }^{\mathrm{j}}>\mathrm{a}$ means requires a model convention. Any convention must specify what $\rho_{t+1}^{j}>0$ means and this depends upon $\Psi_{t+1}\left(u_{t}^{j}\right)$. In an economy with $\left(\lambda_{\mathrm{y}}^{\mathrm{x}}>0, \lambda_{\mathrm{y}}^{\mathrm{z}^{1}}>0, \lambda_{\mathrm{y}}^{\mathrm{z}^{2}}>0\right), \rho_{\mathrm{t}+1}^{\mathrm{j}}>0$ raises $j$ 's forecast of $w_{t+1}^{j}=\left(x_{t+1}^{j}, z_{t+1}^{1 j}, z_{t+1}^{2 j}\right)$. This motivates a formal definition of bull and bear states.

Definition: Let $Q^{j}$ be the probability belief of agent $j$. Then $u_{t}{ }^{j}$ is said to be a bull state for agent $j$ if $E_{Q^{j}}\left[w_{t+1}^{j} \mid u_{t}^{j}, H_{t}\right]>E_{m}\left(w_{t+1} \mid H_{t}\right) \Leftrightarrow E_{Q^{j}}\left[\Psi_{t+1}\left(u_{t}{ }^{j}\right) \mid u_{t}{ }^{j}, H_{t}\right]>0$, a bear state for agent $j$ if $E_{Q^{j}}\left[w_{t+1}^{j} \mid u_{t}^{j}, H_{t}\right]<E_{m}\left(w_{t+1} \mid H_{t}\right) \Leftrightarrow E_{Q^{j}}\left[\Psi_{t+1}\left(u_{t}^{j}\right) \mid u_{t}^{j}, H_{t}\right]<0$.

The random vector $\Psi_{t+1}\left(u_{t}{ }^{j}\right)$ depends upon parameters while it's expected value is

$$
E_{Q^{j}}\left[\Psi_{t+1} \mid u_{t}^{j}, H_{t}\right]=\left(\begin{array}{l}
\lambda_{y}^{x} E_{Q^{j}} \rho_{t+1}^{j}\left(u_{t}^{j}\right) \\
\lambda_{y}^{z^{1}} E_{Q^{j}} \rho_{t+1}^{j}\left(u_{t}^{j}\right) \\
\lambda_{y}^{z^{2}} E_{Q^{j}} \rho_{t+1}^{j}\left(u_{t}^{j}\right)
\end{array}\right) .
$$


Hence, if $\lambda_{y}^{\mathrm{x}}>0$ the condition $\mathrm{u}_{\mathrm{t}}^{\mathrm{j}}>\mathrm{a}$ says agent $\mathrm{j}$ is a bull who is optimistic about date $\mathrm{t}+1$ dividend growth being above normal. If $\left(\lambda_{y}^{z^{1}}>0, \lambda_{y}^{z^{2}}>0\right), u_{t}^{j}>a$ says agent $j$ believes date $t+1$ market state of belief will be above normal. Higher market optimism implies higher future capital gains and hence higher total returns. "Normal" is defined by the empirical forecast under $m$. In the development below we study two types of economies which we now define.

Economy 1: for all agents $\lambda_{\mathrm{y}}^{\mathrm{x}}>0, \lambda_{\mathrm{y}}^{\mathrm{z}^{1}}>0, \lambda_{\mathrm{y}}^{\mathrm{z}^{2}}>0$ and bear states are more frequent, while $\mathrm{u}_{\mathrm{t}}^{\mathrm{j}}>$ a means agent $\mathrm{j}$ is optimistic about dividend growth and stock returns at $\mathrm{t}+1$ $\mathrm{u}_{\mathrm{t}}^{\mathrm{j}}<\mathrm{a}$ means agent $\mathrm{j}$ is pessimistic about dividend growth and stock returns at $\mathrm{t}+1$. Economy 2: for all agents $\lambda_{\mathrm{y}}^{\mathrm{x}}<0, \lambda_{\mathrm{y}}^{\mathrm{z}^{1}}<0, \lambda_{\mathrm{y}}^{\mathrm{z}^{2}}<0$ and bull states are more frequent, while $\mathrm{u}_{\mathrm{t}}^{\mathrm{j}}>\mathrm{a}$ means agent $\mathrm{j}$ is pessimistic about dividend growth and stock returns at $\mathrm{t}+1$ $\mathrm{u}_{\mathrm{t}}^{\mathrm{j}}<\mathrm{a}$ means agent $\mathrm{j}$ is optimistic about dividend growth and stock returns at $\mathrm{t}+1$. What are the beliefs in bull and bear states? Consider Economy I. As $\left(u_{t}{ }^{j}-a\right)$ increase, $\varphi_{1}\left(u_{t}{ }^{j}\right)$ rises and $\varphi_{2}\left(u_{t}^{j}\right)$ declines. Hence when $u_{t}^{j}>a$ an agent increases the positive part of a normal density in $(12 b)$ by a factor $\varphi_{1}\left(u_{t}^{j}\right)>1$ and decreases the negative part by $\varphi_{2}\left(u_{t}^{j}\right)<1$. When $\mathrm{u}_{\mathrm{t}} \mathrm{j}^{\mathrm{j}}<\mathrm{a}$ the opposite occurs: the negative part is shifted up by $\varphi_{2}\left(\mathrm{u}_{\mathrm{t}}{ }^{\mathrm{j}}\right)>1$ and the positive part is shifted down by $\varphi_{1}\left(\mathrm{u}_{\mathrm{t}}{ }^{\mathrm{j}}\right)<1^{14}$. The amplifications $\left(\varphi_{1}(\mathrm{u}), \varphi_{2}(\mathrm{u})\right)$ are defined by $\mathrm{u}^{\mathrm{j}}$, by a and by the"fat tails" parameter $b$. The parameter $b$ measures the degree by which the distribution is shifted per unit of $\left(u_{t}{ }^{j}-a\right)$. In Figure 1 we draw densities of $\rho^{j}\left(u^{j}\right)$ for $u^{j}>a$ and for $u^{j}<a$. These are not normal densities. As $u_{t}^{j}$ varies, the densities of $\rho_{t+1}^{j}\left(u_{t}^{j}\right)$ change. However, the empirical distribution of $u_{t}{ }^{j}$ is normal with zero unconditional mean and hence the empirical distribution of $\rho_{t+1}^{j}\left(u_{t}^{j}\right)$, measured over time, also has these same properties.

\section{FIGURE 1 PLACE HERE}

\footnotetext{
${ }^{14}$ It will become clear that shifts in probability of positive and negative outcomes means changes of probability belief in gains or losses of investments. Hence, it will reflect unequal valuation of gains and losses and this may remind the reader ideas developed in the psychological literature under the heading of Prospect Theory (see Kahneman and Tversky (1979)). Prospect Theory suggests that apart from concavity, it is inherent in the utility of agents to treat a small loss as more significant than an equal gain. Our agents do indeed place heavier weight on losses when they are pessimistic about investment returns and they place a heavier weight on gains when they are optimistic about returns. However, this difference in weight arises because they do not believe that the gains and losses are equally likely. Moreover, under our treatment they may place increased weight either on losses or on gains, depending upon their state of belief.
} 
The parameter a measures asymmetry. It determines the frequency at which agents are bulls. To see why note that if $a=0,(13)$ is symmetric around 0 ( the unconditional mean of $\mathrm{u}^{\mathrm{j}}$ ) and the probability of $\mathrm{u}^{\mathrm{j}}>0$ is $50 \%$. When $\mathrm{a}>0$ the probability of $\mathrm{u}^{\mathrm{j}}>\mathrm{a}$ is less than $50 \%$ and if $\lambda_{\mathrm{y}}^{\mathrm{x}}>0, \lambda_{\mathrm{y}}^{\mathrm{z}^{1}}>0, \lambda_{\mathrm{y}}^{\mathrm{z}^{2}}>0$, the frequency at which $\mathrm{j}$ is pessimistic, exceeds $50 \%$. In a large market this would mean that, on average, a majority of traders is pessimistic about $t+1$ returns. However, "optimism" does not mean a belief in high returns but rather, it is a high probability belief in above normal returns. Also, it is irrational to always be a bull or always be a bear. Hence, if an agent is a bear more than $50 \%$ of the time, the intensity of his optimism (when optimist) must be greater than the intensity of pessimism (when pessimist). "Intensity" means deviations from the empirical probabilities. This discussion shows that when $\lambda_{\mathrm{y}}^{\mathrm{x}}>0, \lambda_{\mathrm{y}}^{\mathrm{z}^{1}}>0, \lambda_{\mathrm{y}}^{\mathrm{z}^{2}}>0$ bears are in the majority and hence an agent is more intense when he is a bull.

Each component of $\Psi_{t+1}\left(u_{t}{ }^{j}\right)$ is a sum of two random variables. The first is as in Figure 1 and the second is normal. In Figure 2 we draw two densities of $\Psi_{t+1}\left(u_{t}{ }^{j}\right)$. Each is a convolution of a normal density with a density as in Figure 1: one for $\mathrm{u}^{\mathrm{j}}>\mathrm{a}$ and one for $\mathrm{u}^{\mathrm{j}}<\mathrm{a}$, showing each has a "fat tail" relative to the empirical distribution. Note that since b measures the intensity by which the positive and negative portions of the distribution in Figure 1 are shifted, it measures the degree of fat tails in the distributions of $\Psi_{t+1}\left(u_{t}^{j}\right)$. Since the empirical distribution of $u^{j}$ is normal, when $u^{j}$ varies over time, averaging of the densities $\rho^{j}\left(u^{j}\right)$ over $u^{j}$ generates a random variable which is normal. This averaging of densities is the way we check the rationality conditions.

\section{FIGURE 2 PLACE HERE}

The parameters a and b are central as they regulate asymmetry and intensity of the agents' confidence about future states. The feasible values of the parameters are determined by the rationality conditions developed in Appendix B. The question we ask is then simple: are there feasible values of the parameters so the model replicates the empirical record of the U.S. economy? Moreover, what is the economic interpretation of the behavior implied by these parameter values?

\section{The Explicit Form of the Perception Models}

We can now combine the development up to now to formulate the final form of the perception models of the agents: 


$$
\begin{aligned}
& \left.x_{t+1}^{j}=\left(1-\lambda_{x}\right) x^{*}+\lambda_{x} x_{t}+\lambda_{y}^{x} j_{t+1}^{j} u_{t}^{j}\right)+\tilde{\rho}_{t+1}^{x^{j}} \\
& z_{t+1}^{j 1}=\lambda_{z^{1}} z_{t}^{1}+\lambda_{x}^{z^{1}}\left(x_{t}-x^{*}\right)+\lambda_{y}^{z^{1}} \rho_{t+1}^{j}\left(u_{t}^{j}\right)+\tilde{\rho}_{t+1}^{z^{j 1}} \\
& z_{t+1}^{j 2}=\lambda_{z^{2}} z_{t}^{2}+\lambda_{x}^{z^{2}}\left(x_{t}-x^{*}\right)+\lambda_{y^{j}}^{z^{2}} \rho_{t+1}^{j}\left(u_{t}^{j}\right)+\tilde{\rho}_{t+1}^{z^{j 2}} \\
& y_{t+1}^{j}=\lambda_{z^{j}} y_{t}^{j}+\lambda_{x}^{z^{j}}\left(x_{t}-x^{*}\right)+\tilde{\rho}_{t+1}^{y^{j}} .
\end{aligned}
$$

$\tilde{\rho}_{t+1}^{\mathrm{j}}=\left(\tilde{\rho}_{t+1}^{\mathrm{x}^{\mathrm{j}}}, \tilde{\rho}_{\mathrm{t}+1}^{\mathrm{z}^{\mathrm{j} 1}}, \tilde{\rho}_{\mathrm{t}+1}^{\mathrm{z}^{\mathrm{j}}}, \tilde{\rho}_{\mathrm{t}+1}^{\mathrm{y}^{\mathrm{j}}}\right)$ is i.i.d. Normal with mean zero and covariance matrix $\Omega$ to be specified.

We note two items. First, the terms $\lambda_{y^{j}}^{x} \rho^{j}\left(u_{t}^{j}\right)$ in the first equation reflects diverse beliefs about dividend shocks and about interpreting public news $\mathrm{x}_{\mathrm{t}}$ for forecasting $\mathrm{x}_{\mathrm{t}+1}$. The agent's forecast of $x_{t+1}$ is $E_{Q_{t}} x_{t+1}^{j}=\lambda_{x} x_{t}+\lambda_{y^{j}}{ }^{x} E_{Q_{t}^{j}} \rho_{t+1}^{j}\left(u_{t}^{j}\right)$, not $\lambda_{x} x_{t}$ as in $(6 a) . \lambda_{y}{ }^{j} E_{Q_{t}{ }^{j}} \rho_{t+1}^{j}\left(u_{t}^{j}\right)$ measures the agent's forecasted deviation from the value in (6a). Second, the terms $\lambda_{y}^{21} \rho_{t+1}\left(u_{t}^{j}\right), \lambda_{y}^{z 2} \rho_{t+1}\left(u_{t}^{j}\right)$ in the third and fourth equations measure the effect of $j$ 's belief on his forecast of the belief of others $\left(z_{t+1}^{k 1}, z_{t+1}^{k 2}\right)$ at $t+1$. Since prices depend on $\left(z_{t+1}^{1}, z_{t+1}^{2}\right)$, the terms $\lambda_{y}^{z^{j 1}} \rho_{t+1}^{j}\left(u_{t}^{j}\right)$ and $\lambda_{y}^{j^{j 2}} \rho_{t+1}^{j}\left(u_{t}^{j}\right)$ add heterogeneity to forecasts of $t+1$ prices and endogenous variables. These are the key forces which generate market volatility.

\section{4c The Rationality of Belief Conditions}

As noted before, the rationality principle requires that

$$
\Psi_{t+1}\left(u_{t}^{j}\right)=\left(\begin{array}{c}
\lambda_{y^{j}}^{x} \rho_{t+1}^{j}\left(u_{t}^{j}\right)+\tilde{\rho}_{t+1}^{x^{j}} \\
\lambda_{y^{j}}^{z^{j 1}} \rho_{t+1}^{j}\left(u_{t}^{j}\right)+\tilde{\rho}_{t+1}^{z^{j 1}} \\
\lambda_{y}^{z^{j}} \rho_{t+1}^{j}\left(u_{t}^{j}\right)+\tilde{\rho}_{t+1}^{z^{j 2}}
\end{array}\right) \text { has the same joint empirical distribution as } \rho_{t+1}=\left(\begin{array}{c}
\rho_{t+1}^{x} \\
\rho_{t+1}^{z^{1}} \\
\rho_{t+1}^{z^{2}}
\end{array}\right) \text {. }
$$

In Appendix B we show two facts: (a) that these conditions fully specify the covariance matrix $\Omega$ of the innovations $\tilde{\rho}_{t}^{j}$, and (b) that $\Psi_{t+1}\left(\rho_{t+1}^{j}\left(u_{t}^{j}\right)\right)$ is serially uncorrelated.

\section{Positive Definiteness of $\Omega$ as Implied Restriction of the Rationality Conditions}

We study here only the symmetric case and for the empirical distribution we assume

$$
\lambda_{\mathrm{z}}=\lambda_{\mathrm{z}^{1}} \equiv \lambda_{\mathrm{z}^{2}} \quad, \quad \lambda_{\mathrm{x}}^{\mathrm{z}}=\lambda_{\mathrm{x}}^{\mathrm{z}^{1}} \equiv \lambda_{\mathrm{x}}^{\mathrm{z}^{2}} .
$$

For the beliefs we use the symmetric notation 


$$
\lambda_{\mathrm{y}}^{\mathrm{x}}=\lambda_{\mathrm{y}^{2}}^{\mathrm{x}} \equiv \lambda_{\mathrm{y}}^{\mathrm{x}}, \quad \lambda_{\mathrm{y}}^{\mathrm{z}^{11}}=\lambda_{\mathrm{y}}^{\mathrm{z}^{12}}=\lambda_{\mathrm{y}^{2}}^{\mathrm{z}^{21}}=\lambda_{\mathrm{y}^{2}}^{\mathrm{z}^{22}} \equiv \lambda_{\mathrm{y}}^{\mathrm{z}}, \quad \mathrm{a}^{1}=\mathrm{a}^{2} \equiv \mathrm{a} \quad \text { and } \quad \mathrm{b}^{1}=\mathrm{b}^{2} \equiv \mathrm{b} .
$$

Hence, beliefs are determined by four parameters $\left(\lambda_{y}^{\mathrm{x}}, \lambda_{\mathrm{y}}^{\mathrm{z}}, \mathrm{a}, \mathrm{b}\right)$. These are then drastically restricted by the condition that $\Omega$ is positive definite. Some implications of this condition are:

- $\quad \sigma_{\mathrm{x}}=0.03256$ implies $\left|\lambda_{\mathrm{y}}^{\mathrm{x}}\right|<0.03$. The covariance structure further restricts $\left|\lambda_{\mathrm{y}}^{\mathrm{x}}\right|<0.028$.

- The covariance structure implies that $\left|\lambda_{\mathrm{y}}^{\mathrm{z}}\right|<0.35$.

- $\quad$ The parameter $\mathrm{b}$ has a feasible range between 0 and 9 .

\section{4d Model Parameters and a Note on Computed Equilibria}

Our goal is to explore the effect of belief parameters $\left(\lambda_{y}^{\mathrm{x}}, \lambda_{\mathrm{y}}^{\mathrm{z}}, \mathrm{a}, \mathrm{b}\right)$ on market volatility and provide an economic interpretation. We also test which of the two economies (Economy 1 vs. Economy 2) is more compatible with the data. For Economy 1 we select $\lambda_{\mathrm{y}}^{\mathrm{x}}=0.025, \lambda_{\mathrm{y}}^{\mathrm{z}}=0.30$ which are positive and as large as possible in the feasible region. ${ }^{15}$ Setting them as high as consistent with rationality allows a focused discussion of the effect of the parameters $(a, b)$ in the following way. First, given the selected values of $\left(\lambda_{y}^{\mathrm{x}}, \lambda_{\mathrm{y}}^{\mathrm{z}}\right)$, we ask if there exist values of the asymmetry parameter a and intensity of fat tails parameter b such that an economy with these parameters generates volatility with characteristics that are familiar from the data? Second, what are the qualitative properties of economies with such parameter values?

We compute equilibria in this paper using perturbation methods and utilizing a program developed by Hehui Jin (see Jin and Judd (2002) and Jin (2003) ). A solution is declared to be an equilibrium if the following holds: (i) a model is approximated by at least second order derivatives; (ii) errors in market clearing conditions and Euler equations are less than $10^{-3}$. In Appendix $\mathrm{C}$ we provide more details on our computational model.

\section{Characteristics of Volatility I: Moments}

We now study the moments of the time series generated by our model. Intensity of fat tails

15 The feasible set is open as it requires the covariance matrix to be positive definite hence no maximal values can be taken. The objective is then is to set the parameters so that they are close to the boundary but do not destabilize the computational procedure, generating error in the Euler Equations. For example, $\lambda_{\mathrm{y}}^{\mathrm{x}}=0.027$ is feasible but $\lambda_{y}^{x}=0.028$ is not hence $\lambda_{y}^{x}=0.025$ is sufficiently far from the boundary to enable computed solutions with low error in the Euler Equations . 
and asymmetry in beliefs are crucial components of our theory. They enable the model to generate time series that match the U.S. record. But, what is the role of intensity and asymmetry in the propagation of volatility and which of the two types of economies discussed earlier are compatible with the empirical record? The answers to these questions show how the model matches the data. However, they also explain on a theoretical level the forces which generate volatility and risk premia without reference to the particular values of the moments recorded in the U.S.

\subsection{The Role of Intensity}

We thus start with an experiment disabling the asymmetry parameter by setting $\mathrm{a}=0$ while varying the intensity parameter $b$. Keeping in mind that parameters of the real economy imply riskless steady state values $\mathrm{q}^{\mathrm{s} *}=16.57, \mathrm{R}^{*}=\mathrm{r}^{*}=7.93$, we vary $\mathrm{b}$ from $\mathrm{b}=1$ up to a value at which the mean riskless rate reaches the value of $0.5 \%$. Table 3 reports the results. These show

the market exhibits substantial non - linearity in response to rising market volatility as $\mathrm{q}^{\mathrm{s}}$ and $\sigma_{\mathrm{q}}$ s $d o$ not change monotonically with market volatility. However, as market volatility increases the following change in a monotonic manner:

- $\quad$ The risky rate $\mathrm{R}$ rises from $7.89 \%$ to $11.40 \%$

- The standard deviation $\sigma_{\mathrm{R}}$ of the risky rate rises from $4.72 \%$ to $24.23 \%$

- $\quad$ The riskless rate $\mathrm{r}$ declines from $7.48 \%$ to $0.55 \%$

- $\quad$ The correlation coefficient $\rho(x, R)$ declines from 0.76 to 0.11

- $\quad$ The Sharp Ratio (Shrp) rises from 0.09 to 0.45 .

Without a detailed numerical demonstration we add the fact that the pattern observed in Table 3 remains the same for all feasible belief parameter of the model. Hence, the reasoning offered below does not depend upon parameter values such as $\left(\lambda_{\mathrm{y}}^{\mathrm{x}}, \lambda_{\mathrm{y}}^{\mathrm{z}}\right)$.

Table 3 shows the riskless rate declines towards $1 \%$ simply because the RBE becomes more volatile. This affects both the volatility of individual consumption growth rates as well as their correlation with the growth rate of aggregate consumption. In an REE this correlation is close to 1 but not in an RBE where variability of individual consumption growth depends upon the agents' beliefs. The low observed riskless rate has been a central problem in the equity premium puzzle debate (see Weil (1989)) and the effect of the parameter b goes to the heart of this issue. 
Our theory offers the intuitive explanation that non normal belief densities with fat tails and high intensity propagate high market volatility hence risk, making financial safety costly.

\section{Table 3: The Effect of Pure Intensity}

(all moments are annualized)

\begin{tabular}{|c|c|c|c|c|c|c|c|c|}
\hline $\begin{array}{l}\mathrm{b} \Rightarrow \\
\mathrm{a}=0\end{array}$ & 1.00 & 2.00 & 3.00 & 4.00 & 4.25 & 4.75 & 4.95 & Record \\
\hline$q^{s}$ & 16.92 & 17.60 & 18.88 & 19.99 & 19.74 & 17.27 & 15.20 & 25 \\
\hline$\sigma_{\mathrm{g}} \mathrm{s}$ & $0.63 \%$ & $1.42 \%$ & $2.51 \%$ & $3.87 \%$ & $4.12 \%$ & $4.07 \%$ & $3.72 \%$ & $7.1 \%$ \\
\hline $\mathrm{R}^{\mathrm{q}}$ & $7.89 \%$ & $7.86 \%$ & $7.86 \%$ & $8.28 \%$ & $8.61 \%$ & $10.11 \%$ & $11.40 \%$ & $7.0 \%$ \\
\hline$\sigma_{\mathrm{R}}$ & $4.72 \%$ & $7.42 \%$ & $11.30 \%$ & $16.37 \%$ & $17.90 \%$ & $21.84 \%$ & $24.23 \%$ & $18.0 \%$ \\
\hline$r^{\kappa}$ & $7.48 \%$ & $7.13 \%$ & $6.61 \%$ & $5.55 \%$ & $4.94 \%$ & $2.44 \%$ & $0.55 \%$ & $1.0 \%$ \\
\hline$\sigma_{\mathrm{r}}$ & $2.45 \%$ & $3.71 \%$ & $3.67 \%$ & $1.98 \%$ & $1.48 \%$ & $3.24 \%$ & $5.26 \%$ & $5.7 \%$ \\
\hline & $0.43 \%$ & $0.72 \%$ & $1.24 \%$ & $2.74 \%$ & $3.67 \%$ & $7.67 \%$ & $10.86 \%$ & $6.0 \%$ \\
\hline$\rho^{p}(x, R)$ & 0.76 & 0.46 & 0.28 & 0.18 & 0.16 & 0.12 & 0.11 & 0.12 \\
\hline Shrp & 0.09 & 0.10 & 0.11 & 0.17 & 0.20 & 0.35 & 0.45 & 0.33 \\
\hline
\end{tabular}

Now compare Table 3 with the empirical record. As volatility increases and the riskless rate $r$ reaches $0.5 \%$ we see that (i) $q^{s}$ declines below 25 , (ii) $R$ rises above $7.0 \%$, (iii) $\sigma_{R}$ rises above $18.0 \%$, (iv) the Sharp Ratio rises above 0.33. A moment's reflection shows that these are reasonable conclusions for a symmetric volatile economy. In a symmetric economy bear and bull states are perfectly symmetric: each bull market state has an exact opposite bear market state. Such symmetry implies that as risk level increases, the riskless rate should decline as the cost of safety increase and the risky rate should rise for symmetric reasons. For the riskless rate to decline but for the risky rate to remain the same in response to market volatility, there must be some asymmetry in the belief structure to induce a rise in the price to dividend ratio. The instrument for asymmetry is the parameter a which provides a measure of the time frequency of bear states. This frequency is $\Phi\left(\frac{\mathrm{a}}{\sigma_{\mathrm{u}}}\right)$, and since a $>0$ we conclude that $\Phi\left(\frac{\mathrm{a}}{\sigma_{\mathrm{u}}}\right)>50 \%$ ( $\Phi$ is the cumulative standard normal). But when $a>0$ the tail on the bull side must compensate for the higher frequency on the bear side hence the bull distribution must be more skewed than the bear distribution. As discussed earlier, there are two asymmetries within our model which define two types of economies that we consider. In Economy 1 bear states are more frequent while in Economy 2 bull states are more frequent.

\subsection{Which Asymmetry?}

In Table 4 we test the two asymmetries with the following experiment. We fix $b=4.85$, $\mathrm{a}=0.40$ and pick three random pairs of values for $\lambda_{\mathrm{y}}^{\mathrm{x}}>0, \lambda_{\mathrm{y}}^{\mathrm{z}}>0$. We then simulate the equilibria for these pairs and for the negative values of the same pairs. The aim is only to examine the effect 
of switching positive to negative signs. The results for $\lambda_{\mathrm{y}}^{\mathrm{x}}<0, \lambda_{\mathrm{y}}^{\mathrm{z}}<0$, on the left side of Table 4 , are entirely counter-factual. Asymmetry according to which bull states are more frequent imply too low Price/Dividend ratio and too high risky and riskless rates. These qualitative conclusions remain the same for all $\mathrm{a}>0, \mathrm{~b}>0, \lambda_{\mathrm{y}}^{\mathrm{x}}>0, \lambda_{\mathrm{y}}^{\mathrm{z}}>0$ for which this experiment is feasible. Hence we reject the hypothesis that bull states are more frequent. However, we now give an intuitive explanation for the higher Price/Dividend ratio and the lower returns on the right side of Table 4.

Table 4: Which Asymmetry? (all moments are annualized)

Economy 2

\begin{tabular}{|l|l|l|l|l|l|l|}
\hline $\begin{array}{l}\lambda_{\mathrm{y}}^{\mathrm{x}}=-0.025 \\
\lambda_{\mathrm{y}}^{\mathrm{z}}=-0.26\end{array}$ & $\begin{array}{l}\lambda_{\mathrm{y}}^{\mathrm{x}}=-0.023 \\
\lambda_{\mathrm{y}}^{\mathrm{z}}=-0.28\end{array}$ & $\begin{array}{l}\lambda_{\mathrm{y}}^{\mathrm{x}}=-0.023 \\
\lambda_{\mathrm{y}}^{\mathrm{z}}=-0.30\end{array}$ & & $\begin{array}{l}\lambda_{\mathrm{y}}^{\mathrm{x}}=0.023 \\
\lambda_{\mathrm{y}}^{\mathrm{z}}=0.30\end{array}$ & $\begin{array}{l}\lambda_{\mathrm{y}}^{\mathrm{x}}=0.023 \\
\lambda_{\mathrm{y}}^{\mathrm{z}}=0.28\end{array}$ & $\begin{array}{l}\lambda_{\mathrm{y}}^{\mathrm{x}}=0.025 \\
\lambda_{\mathrm{y}}^{\mathrm{z}}=0.26\end{array}$ \\
\hline 6.20 & 6.34 & 5.66 & $\mathrm{q}^{\mathrm{s}}$ & 26.92 & 29.74 & 34.55 \\
$0.88 \%$ & $0.86 \%$ & $0.80 \%$ & $\sigma_{\mathrm{q}^{\mathrm{s}}}$ & $4.98 \%$ & $5.95 \%$ & $7.97 \%$ \\
$19.33 \%$ & $18.87 \%$ & $20.95 \%$ & $\mathrm{R}^{\mathrm{n}}$ & $6.96 \%$ & $6.74 \%$ & $6.72 \%$ \\
$13.91 \%$ & $13.44 \%$ & $14.23 \%$ & $\sigma_{\mathrm{R}}$ & $16.64 \%$ & $17.44 \%$ & $20.05 \%$ \\
$23.40 \%$ & $22.96 \%$ & $24.57 \%$ & $\mathrm{r}$ & $3.06 \%$ & $3.85 \%$ & $3.28 \%$ \\
$26.67 \%$ & $25.75 \%$ & $27.76 \%$ & $\sigma_{\mathrm{r}}$ & $2.94 \%$ & $1.97 \%$ & $1.89 \%$ \\
$-4.07 \%$ & $-4.09 \%$ & $-3.62 \%$ & $\mathrm{e}_{\mathrm{p}}$ & $3.90 \%$ & $2.89 \%$ & $3.44 \%$ \\
0.34 & 0.35 & 0.34 & $\rho(x, \mathrm{R})$ & 0.17 & 0.16 & 0.13 \\
-0.29 & -0.30 & -0.25 & Shrp & 0.23 & 0.17 & 0.17 \\
\hline
\end{tabular}

Agents in Economy 1 are in bear states at a majority of dates. This means that at more than $50 \%$ of the dates they do not expect to make abnormal stock returns in the subsequent date. They expect dividends to grow slower than normal and their stock portfolio to produce lower than normal returns. The question is: what is the resulting equilibrium "normal" Price/Dividend ratio? To answer this question we distinguish between the price of the stock and the Price/Dividend ratio $q^{s}$. The non - normalized Euler equation (4a') is $\left(C_{t}^{j}\right)^{-\gamma} \tilde{q}_{t}^{s}=\beta E_{Q_{t}^{j}}\left[\left(C_{t+1}^{j}\right)^{-\gamma}\left(D_{t+1}+\tilde{q}_{t+1}^{s}\right)\right]$. Hence, if an agent becomes bullish about future dividend growth rate his demand for the stock increases and if most agents become optimistic, equilibrium stock price rises. If a majority become bearish about future dividend growth the price declines. The situation is different for $\mathrm{q}^{\mathrm{s}}$ as can be seen from the normalized Euler equation (4a) $\left(c_{t}\right)^{j}{ }^{-\gamma} q_{t}^{s}=\beta E_{Q_{t}}\left[\left(c_{t+1}^{j}\right)^{-\gamma}\left(1+q_{t+1}^{s}\right) e^{(1-\gamma) x_{t+1}}\right]$. Suppose an agents' perceived conditional distribution of $x_{t+1}$ is shifted downward. The effect on equilibrium $q^{s}$ depends upon the elasticity of substitution between $c_{t}$ and $c_{t+1}$ which is $-\frac{1}{\gamma}$. Being pessimistic about future returns is the same as considering present consumption as less expensive. Since $\gamma=2$, for a pessimistic agent a $1 \%$ decreased relative cost of today's consumption leads only to a $0.5 \%$ increase in today's consumption. Equivalently, in an economy 
where agents are, on average, more frequently bearish about $x_{t+1}$ the time average of $q^{s}$ is higher. This implies that in an economy where agents are, on average, bearish more than $50 \%$ of the time the average price to dividend ratio is higher and the average rate of return is lower than in an economy where agents are, on average, bullish more than $50 \%$ of the dates. This is exactly what happens in Table 4.

We do not have direct evidence in support of our conclusion that the frequency of bear states is, on average, higher than 50\%. However, this conclusion is supported by the empirical fact that, on average, most above normal stock returns are made over relatively small proportion of time in which asset prices rally strongly (see Shilling(1992)). An agent who invests for the long run experiences large above normal returns only a small proportion of time. Hence, on average, the proportion of time that one may expect to make above normal return is much less than $50 \%{ }^{16}$. Additional indirect support comes from the psychological literature which suggests agents place heavier weight on losses than on gains. In our treatment this is indeed the case at majority of dates due to the fact that on those dates agents believe abnormally lower return are more likely than higher. It follows from the RB principle that the higher frequency of bear states implies that when in bull states, an agent's intensity of optimism is higher than the intensity of pessimism. This means the average size of the positive tail in the belief densities is bigger than the average size of the negative tail. When in optimistic states our agents expect to make abnormal returns and with positive correlation in beliefs among such agents, these beliefs can rationalize market behavior that may look like a local bubble. Let us explain this fact.

The asymmetry results (i.e. a $>0$ ) implies optimistic agents tend to be intense. We have noted that beliefs are highly correlated across agents hence we should expect to observe periods of high optimism across a majority of agents. When the level of optimism is very high, agents expect to make such high returns on their investments that they want to borrow and finance present and future consumption. This they cannot all do since bonds are in zero net supply. At such dates the only way markets can clear is by exhibiting sharp rises in stock prices together with high borrowing

16 Shilling(1992) shows that during the 552 months from January 1946 through December of 1991 the mean real annual total return on the Dow Jones Industrials was 6.7\%. However, if an investor missed the 50 strongest months the real mean annual return over the other 502 months was $-0.8 \%$. Hence the financial motivation to time the market is very strong, as is the case with the agents in our model 
rates. Hence, our theory predicts that we should expect to observe rapidly rising stock prices induced by bursts of correlated optimism together with high realized growth rates of dividends. We would also expect to see crashes induced by correlated pessimistic agents together with low realized growth rates of dividends.

\subsection{Matching the Moments}

We now combine the effects of intensity and asymmetry to exhibit a region of parameters where the simulated moments are close to the empirical record. Table 5 provides a summary.

Table 5: The Combined Effect of Intensity and Asymmetry (all moments are annualized)

\begin{tabular}{|c|c|c|c|c|c|}
\hline & $\underset{\Downarrow}{b}, a \Rightarrow$ & 0.10 & 0.25 & 0.40 & \\
\hline $\begin{array}{l}\mathrm{q}^{\mathrm{s}} \\
\sigma_{\mathrm{q}^{\mathrm{s}}} \\
\mathrm{R} \\
\sigma_{\mathrm{R}} \\
\mathrm{r}^{\mathrm{m}} \\
\sigma_{\mathrm{r}} \\
\mathrm{e}_{\mathrm{p}}(\mathrm{x}, \mathrm{R}) \\
\mathrm{\rho}_{\text {Shrp }}\end{array}$ & 4.75 & $\begin{array}{r}17.40 \\
4.04 \% \\
9.97 \% \\
21.38 \% \\
2.68 \% \\
3.05 \% \\
7.29 \% \\
0.12 \% \\
0.34\end{array}$ & $\begin{array}{r}23.22 \\
4.90 \% \\
8.06 \% \\
19.40 \% \\
2.38 \% \\
3.22 \% \\
5.67 \% \\
0.14 \% \\
0.29\end{array}$ & $\begin{array}{c}28.06 \\
5.52 \% \\
7.03 \% \\
18.00 \% \\
2.19 \\
3.44 \% \\
4.84 \% \\
0.15 \% \\
0.27\end{array}$ & Record \\
\hline $\begin{array}{l}\mathrm{q}^{\mathrm{s}} \\
\sigma_{\mathrm{q}^{\mathrm{s}}} \\
\mathrm{R} \\
\sigma_{\mathrm{R}} \\
\mathrm{r}^{\mathrm{m}} \\
\sigma_{\mathrm{r}} \\
\mathrm{e}_{\mathrm{p}} \\
\rho_{\mathrm{p}}(\mathrm{x}, \mathrm{R}) \\
\text { Shrp }\end{array}$ & 4.85 & $\begin{array}{r}16.51 \\
3.91 \% \\
10.49 \% \\
22.40 \% \\
1.87 \% \\
3.92 \% \\
8.62 \% \\
0.12 \% \\
0.38\end{array}$ & $\begin{array}{r}22.04 \\
4.62 \% \\
8.36 \% \\
19.81 \% \\
1.51 \% \\
4.08 \% \\
6.85 \% \\
0.14 \% \\
0.35\end{array}$ & $\begin{array}{c}26.61 \\
5.09 \% \\
7.22 \% \\
18.05 \% \\
1.24 \% \\
4.38 \% \\
5.98 \% \\
0.15 \% \\
0.33\end{array}$ & $\begin{array}{l}25 \\
7.1 \% \\
7.0 \% \\
18.0 \% \\
1.0 \% \\
5.7 \% \\
6.0 \% \\
0.1 \% \\
0.33 \\
\end{array}$ \\
\hline $\begin{array}{l}\mathrm{q}^{\mathrm{s}} \\
\sigma_{\mathrm{q}} \\
\mathrm{R}^{\mathrm{q}} \\
\sigma_{\mathrm{R}} \\
\mathrm{r} \\
\sigma_{\mathrm{r}} \\
\mathrm{e}_{\mathrm{p}} \\
\rho(\mathrm{x}, \mathrm{R}) \\
\text { Shrp }\end{array}$ & 4.95 & $\begin{array}{c}15.45 \\
3.72 \% \\
11.17 \% \\
23.62 \% \\
0.89 \% \\
4.96 \% \\
10.27 \% \\
0.11 \% \\
0.44\end{array}$ & $\begin{array}{r}20.59 \\
4.26 \% \\
8.76 \% \\
20.29 \% \\
0.44 \% \\
5.15 \% \\
8.32 \% \\
0.13 \% \\
0.41\end{array}$ & $\begin{array}{c}24.77 \\
4.57 \% \\
7.50 \% \\
18.10 \% \\
0.07 \% \\
5.55 \% \\
7.43 \% \\
0.15 \% \\
0.41\end{array}$ & \\
\hline
\end{tabular}

It is clear from Table 5 that for values of $\mathrm{b}$ around $4.75-5.00$ and $\mathrm{a}$ around $0.25-0.40$ all moments are close to the moments observed in the market. Most significant is the fact that around this region of the parameter space all model statistics match simultaneously the moments and premium in the empirical record. We show later that the model with these parameter values exhibit qualitative dynamic properties such as forecastability of returns and stochastic volatility which are similar to those observed in the empirical record. 
The fact that our model matches simultaneously the moments and the diverse phenomena associated with market volatility provides strong support for our theory. However, a property of simultaneous explanation of diverse phenomena by a single model rather than a specialized model for each phenomenon, is a crucial property any good theory of market volatility must have.

The results in Table 5 are due primarily to the two factors discussed: intensity of fat tails and asymmetry. We have already commented on evidence regarding asymmetry. We add the fact that it is well documented that the distribution of asset returns exhibit fat tails (e.g. see Fama (1965) and Shiller (1981)). It is natural to ask where these tails come from. Our theory proposes that these fat tails in returns come from fat tails in the probability models of agents' beliefs.

We do not propose that the exact parameter values of $a$ or $b$ have particular significance. Indeed, since the parameters $\lambda_{y}^{\mathrm{x}}>0, \lambda_{\mathrm{y}}^{\mathrm{z}}>0$ also measure intensity of optimism, there is some substitution between $\left(\lambda_{y}^{\mathrm{x}}, \lambda_{\mathrm{y}}^{\mathrm{z}}\right)$ and $\mathrm{b}$ hence there exists a manifold of parameter values for which the model simulations would approximate the empirical record . Our procedure has been to select the largest feasible values of $\lambda_{y}^{\mathrm{x}}>0, \lambda_{\mathrm{y}}^{\mathrm{z}}>0$ and then seek values for $(\mathrm{a}, \mathrm{b})$ to match the data. Table 5 is the results. However, the stronger component of our conclusions is qualitative. We maintain that our theoretical conclusion are general and consist of three parts:

\section{Asset pricing is a non stationary process reflecting technological and institutional} change in our modern economy. As a result, the true underlying process is not known, giving rise to a wide diversity of beliefs about profitability of investments. This diversity is the main mechanism for propagating market volatility.

2. The first factor of volatility is the high intensity of fat tails of the agents' conditional densities: it is the crucial force which generates volatility and low riskless rate.

3. The second component of market volatility is the asymmetry in the belief densities giving rise to markets in which the frequency of bear states is higher than $50 \%$.

We also add that we arrived at our conclusions without specifying the formal subjective belief formation models of the agents. All we specified is how subjective states of belief affect the deviation of the agents' forecasts from the stationary empirical forecasts. Indeed, from the point of view of a general equilibrium, this is all that matters. Hence, the role of the Principle of Rationality consists of two parts. First, it provides the restrictions on the covariance matrix $\Omega$ of the belief 
innovations and consequently our modeling choice is restricted only to the parameters $\left(\lambda_{\mathrm{y}}^{\mathrm{x}}, \lambda_{\mathrm{y}}^{\mathrm{z}}, \mathrm{a}, \mathrm{b}\right)$. Second, the Principle of Rationality implies that asymmetry in the frequency of bear or bull states is compensated by asymmetry in the size of the positive and negative fat tails of the belief densities. These factors turned out to be important for the way in which our model works. The empirical evidence supports this asymmetry as a real phenomenon.

\subsection{Why Does the RBE Resolve the Equity Premium Puzzle?}

Risk premia are compensations for subjective risk perception by risk averse agents. Since normal degrees of risk aversion are less than 10, to explain the observed risk premia we need to explain why volatility of an asset justifies the risk premia the market awards it. In most single agent models, aggregate consumption is exogenous hence volatility is exogenously fixed. In such models the market portfolio is identified with a security whose payoff is aggregate consumption. The Equity Premium Puzzle is the observation that the small volatility of aggregate consumption growth rates cannot justify a large equity premium of this security over riskless debt. Our theory of risk premia, which is based on the diversity of beliefs, takes a very different approach.

Heterogenous beliefs cause diverse individual consumption growth rates even if aggregate consumption is exogenous, which is the case in our model. Hence, individual consumption growth rates need not equal the aggregate rate. Since the agents' states of belief are as essential to them as the stochastic aggregate growth rate, they do not seek to own a portfolio whose payoff is aggregate consumption. Moreover, they disagree on the riskiness of this hypothetical asset. As a result, we do not focus on the relation between asset returns and aggregate consumption growth but instead, on the relation between asset returns and the volatility of individual consumption growth rates. We can thus sum up the factors contributing to the formation of risk premia in Table 5.

(i) Low riskless rate and market volatility. In discussing Table 3 we noted that low riskless rate is a direct consequence of the high volatility of the RBE which creates added perceived risk. This added riskiness is called "Endogenous Uncertainty."

(ii) Higher volatility of individual consumption growth rates and correlation with $x$ which is less than 1. It is clear that to satisfy individual Euler equations the standard problem of the Equity Premium Puzzle cannot arise. The key question is how volatile do individual consumption growth 
rates need to be in order to generate an equity premium of $6 \%$ and a riskless rate of $1 \%$ ? The answer is: not very much. For the case $a=0.40$ and $b=4.85$ in Table 5 we find that although $\sigma_{\mathrm{x}}=0.03256$, the standard deviation of individual consumption growth rates is only 0.038 and the correlation between individual consumption growth rate and $\mathrm{x}$ is only 0.83 (compared to 1.00 in a representative household model). Both figures are compatible with survey data showing individual consumption growth are more volatile than the aggregate. Finally, we note that such volatility of consumption growth cannot occur in a single agent model since in that economy consumption growth rate is determined exogenously. More generally, in our view single agent models are ill suited for the study of phenomena associated with market volatility.

\section{Characteristics of Volatility II: Predictability of Returns and Stochastic Volatility}

We turn now to two other dimensions of asset price dynamics and market volatility with a view to compare predictions of our theory with the empirical record. More specifically, we study the predictability of stock returns and stochastic volatility, or GARCH, properties of stock prices and returns. All results reported below were computed for a sample of 20,000 equilibrium data points generated by Monte Carlo simulation of our model with $a=0.40$ and $b=4.85$ in Table 5 .

\subsection{Predictability of stock returns}

The problem of predictability of risky returns generated an extensive literature in empirical finance (e.g. Fama and French (1988a,1998b), Poterba and Summers (1988), Campbell and Shiller (1988), Timmermann and Paye (2003)). This debate is contrasted with the simple theoretical observation that under risk aversion asset prices and returns are not martingales, hence they contain a predictable component. It appears the disagreement is not about the empirical record itself but about the interpretation of the record and about the stability of estimated forecasting models. For example, Timmermann and Paye (2003) report parameter instability in a sequence of models, estimated for different periods, for which out of sample predictions are unstable and inaccurate. Here we focus only on the empirical record.

We examine the following: (i) Variance Ratio statistic; (ii) autocorrelation of returns and of price/dividend ratios; (iii) regressions of cumulative returns, and (iv) the predictive power of 
the dividend yield. We first introduce notation. Let $\varrho_{t}=\log \left[\frac{\left(q_{t}{ }^{s}+1\right) e^{x_{t}}}{q_{t-1}^{s}}\right]$ be the log of gross one year stock return, $\varrho_{t}^{k}=\sum_{i=0}^{k-1} \varrho_{t-i}$ be the cumulative log-return of length $k$ from $t-k+1$ to $t$, and $\varrho_{t+k}^{k}=\sum_{j=1}^{k} \varrho_{t+j}$ be the cumulative log-return over a k-year horizon from $t+1$ to $t+k$.

\section{1a Variance Ratio Test}

Define the variance-ratio statistic by $\operatorname{VR}(\mathrm{k})=\frac{\operatorname{var}\left(\mathrm{Q}_{\mathrm{t}}^{\mathrm{k}}\right)}{\left(\mathrm{k} \operatorname{var}\left(\mathrm{Q}_{\mathrm{t}}\right)\right)}$. It converges to one if returns are uncorrelated. However, if returns are negatively autocorrelated at some lags, the ratio is less than one. Our results show that there exists a significant higher order autocorrelation in stock returns hence there is a long run predictability which is consistent with U.S. statistics on stock returns, as reported in Poterba and Summers (1988). In Figure 3 we present a plot of the variance ratios computed from our model. For $\mathrm{k}>1$ the ratio is less than 1 and declines with $\mathrm{k}$.

\section{FIGURE 3 PLACE HERE}

In Table 6 we report computed values of the ratios for $\mathrm{k}=1,2, \ldots, 10$ and compare them with ratios computed for U.S. stocks by Poterba and Summers ((1988), Table 2, line 3) for k=1, $2, \ldots, 8$. Our model's prediction is very close to the U.S. empirical record

Table 6: Variance Ratios for NYSE 1926 - 1985

\begin{tabular}{|c|c|c|c|c|c|c|c|c|c|c|}
\hline $\mathrm{k}$ & 1 & 2 & 3 & 4 & 5 & 6 & 7 & 8 & 9 & 10 \\
\hline $\mathrm{VR}(\mathrm{k})$ & 1.00 & 0.84 & 0.72 & 0.63 & 0.57 & 0.50 & 0.45 & 0.41 & 0.37 & 0.34 \\
\hline U.S. & 1.00 & 0.96 & 0.84 & 0.75 & 0.64 & 0.52 & 0.40 & 0.35 & --- & --- \\
\hline
\end{tabular}

\section{$5.1 \mathrm{~b}$ The Autocorrelation of Log-Returns and Price-Dividend ratios}

In Tables 7 we report the autocorrelation function of log annual returns. Our model

Table 7: Autocorrelation of Log-Returns

\begin{tabular}{|c|c|c|}
\hline $\operatorname{corr}\left(\varrho_{\mathrm{t}}, \varrho_{\mathrm{t}-\mathrm{i}}\right)$ & Model & Empirical Record \\
\hline $\mathrm{i}=1$ & -0.163 & 0.070 \\
$\mathrm{i}=2$ & -0.096 & -0.170 \\
$\mathrm{i}=3$ & -0.066 & -0.050 \\
$\mathrm{i}=4$ & -0.035 & -0.110 \\
$\mathrm{i}=5$ & -0.037 & -0.040 \\
\hline
\end{tabular}

predicts negatively autocorrelated returns at all lags. This implies a long horizon mean reversion 
of the kind documented extensively by Poterba and Summers (1988), Fama and French (1998a) and Campbell and Shiller (1988). Thus, apart from the very short returns which exhibit positive autocorrelation, the model reproduces reasonably well the empirical record.

In Table 8 we report the autocorrelation function of the price-dividend ratio. Table shows the model generates a highly autocorrelated price/dividend ratio which matches reasonably well the behavior observed in the U.S. stock market data. The empirical record in Tables 7 and 8 is for NYSE data covering the period 1926-1995 as reported in Barberis et al. (2001).

\section{Table 8: Autocorrelation of Price-Dividend Ratio}

\begin{tabular}{|c|c|c|}
\hline $\operatorname{corr}\left(\mathrm{q}_{\mathrm{t}}^{\mathrm{s}}, \mathrm{q}_{\mathrm{t}-\mathrm{i}}^{\mathrm{s}}\right)$ & Model & Empirical Record \\
\hline $\mathrm{i}=1$ & 0.691 & 0.700 \\
$\mathrm{i}=2$ & 0.479 & 0.500 \\
$\mathrm{i}=3$ & 0.331 & 0.450 \\
$\mathrm{i}=4$ & 0.228 & 0.430 \\
$\mathrm{i}=5$ & 0.147 & 0.400 \\
\hline
\end{tabular}

\section{1c Mean Reversion of Log-Returns}

Mean reversion of stock returns was studied under several models. We compare our results with the results of Fama and French (1988a). Thus, consider the regression model

$$
\varrho_{\mathrm{t}+\mathrm{k}}^{\mathrm{k}}=\alpha_{\mathrm{k}}+\delta_{\mathrm{k}} \varrho_{\mathrm{t}}^{\mathrm{k}}+\mathrm{v}_{\mathrm{t}, \mathrm{k}} \text {. }
$$

The evidence suggests that stock prices have a random-walk and a stationary component (see Fama and French (1988a)), depending upon the horizon k. If there was no stationary component the slopes $\delta_{k}$ in (17) would be 0 for all $k$. If there was no random-walk component the slopes would approach -0.5 for large values of $k$. When prices have both a random walk and a slowly decaying stationary components, the slopes $\delta_{k}$ in (17) should form a U-shaped pattern, starting around 0 for short horizons, becoming more negative as $\mathrm{k}$ increases, and then moving back to 0 as the random walk component begins to dominate at very long horizons. Our model produces exactly this pattern. Figure 4 and Table 9 report such a pattern.

\section{FIGURE 4 PLACE HERE}


Table 9: Properties of Returns from regression (17)

\begin{tabular}{|ccc|ccc|ccc|}
\hline$k$ & $R^{2}$ & $\boldsymbol{\delta}_{k}$ & $k$ & $R^{2}$ & $\boldsymbol{\delta}_{k}$ & $k$ & $R^{2}$ & $\boldsymbol{\delta}_{k}$ \\
\hline 1 & 0.0267 & -0.1634 & 11 & 0.1753 & -0.4186 & 31 & 0.1076 & -0.3282 \\
2 & 0.0637 & -0.2524 & 12 & 0.1708 & -0.4131 & 32 & 0.1009 & -0.3177 \\
3 & 0.0952 & -0.3085 & 13 & 0.1649 & -0.4060 & 33 & 0.0970 & -0.3116 \\
4 & 0.1245 & -0.3528 & 14 & 0.1610 & -0.4012 & 34 & 0.0957 & -0.3093 \\
5 & 0.1544 & -0.3930 & 15 & 0.1564 & -0.3953 & 35 & 0.0922 & -0.3038 \\
6 & 0.1773 & -0.4211 & 16 & 0.1609 & -0.4010 & 36 & 0.0906 & -0.3009 \\
7 & 0.1872 & -0.4327 & 17 & 0.1584 & -0.3979 & 37 & 0.0887 & -0.2977 \\
8 & 0.1915 & -0.4377 & 18 & 0.1571 & -0.3963 & 38 & 0.0886 & -0.2977 \\
9 & 0.1902 & -0.4361 & 19 & 0.1522 & -0.3901 & 39 & 0.0891 & -0.2984 \\
10 & 0.1833 & -0.4281 & 20 & 0.1504 & -0.3878 & 40 & 0.0865 & -0.2940 \\
\hline
\end{tabular}

\section{1d Dividend Yield as a Predictor of Future Stock Returns}

The papers cited above show that the price/dividend ratio is the best explanatory variable of long returns. To test this fact in our model we consider the following regression model

$$
\varrho_{t+k}^{\mathrm{k}}=\zeta_{\mathrm{k}}+\eta_{\mathrm{k}}\left(\mathrm{D}_{\mathrm{t}} / \tilde{\mathrm{q}}_{\mathrm{t}-1}^{\mathrm{s}}\right)+\mathrm{v}_{\mathrm{t}, \mathrm{k}} .
$$

The empirical evidence reported in Fama and French (1988b) shows that the power of the dividend yields to forecast stock returns, measured by regression coefficient $\mathrm{R}^{2}$ of (18), increases with the return horizon. We find that our model captures the main features of the empirical evidence and we report it in Table 10.

Table 10: The behavior of the regression slopes in (18)

\begin{tabular}{|c|c|c|c|c|}
\hline Time horizon & \multicolumn{2}{|c|}{ Model } & \multicolumn{2}{c|}{ Empirical Record } \\
\hline$k$ & $\eta_{k}$ & $R^{2}$ & $\eta_{k}$ & $R^{2}$ \\
\hline 1 & 4.86 & 0.08 & 5.32 & 0.07 \\
2 & 8.30 & 0.14 & 9.08 & 0.11 \\
3 & 10.66 & 0.18 & 11.73 & 0.15 \\
4 & 12.38 & 0.21 & 13.44 & 0.17 \\
\hline
\end{tabular}

To conclude the discussion of predictability, we observe that the empirical evidence reported by Fama and French (1998a, 1998b), Campbell and Shiller (1988), Poterba and Summers (1998) and others is consistent with asset price theories in which time-varying expected returns generate predictable, mean-reverting, components of prices (see Summers (1986)). The important economic question, motivated but left unresolved by these papers, is what drives the predictability 
of returns implied by such mean-reverting components of prices? One component of the answer is the persistence of the dividend growth rate via the equilibrium map (5). Our theory offers a second and stronger persistent mechanism which is also seen in (5). It shows these results are primarily driven by the dynamics of market state of beliefs which exhibit correlation across agents and persistence over time. Agents experience bull and bear states of beliefs. This causes their perception of risk to change and expected returns to vary over time. Equilibrium asset prices are functions of the state of belief which exhibit memory and mean reversion. Hence both prices and returns exhibit these same properties.

\subsection{GARCH Behavior of the Price-dividend Ratio and of the Risky Returns}

The presence of stochastic volatility in asset prices and returns has been well documented (e.g. Bollerslev, Engle and Nelson (1994), Brock and LeBaron (1996)). Indeed, in a partial equilibrium context it is standard to model the price of an asset by a stochastic differential equation which assumes an exogenously driven stochastic volatility. But where does stochastic

volatility come from? The dividend process certainly does not exhibit stochastic volatility hence it cannot be the source of it. One of the most important implication of our theory is that it explains why asset prices and returns exhibit stochastic volatility. We start by presenting in Figures 5 and 6 the results of simulated 500 observations: in Figure 5 we report equilibrium price/dividend ratios and in Figure 6 the associated risky rates of return. Casual inspection of Figures 5 and 6 reveals that volatility is time varying with such time variability in the variance of both prices and returns. However, GARCH behavior is more subtle than volatility clustering as it requires volatility to be persistent, exhibiting serial correlation and this requires a formal test.

\section{FIGURE 5 PLACE HERE FIGURE 6 PLACE HERE}

To formally test the GARCH property of the price/dividend ratio and of the risky return we used the 20,000 equilibrium observations discussed in the previous section. Using these data we estimated the following econometric model of the dynamics of the price/dividend ratio

$$
\begin{aligned}
& \mathrm{q}_{\mathrm{t}}{ }^{\mathrm{s}}=\kappa^{\mathrm{q}}+\mu^{\mathrm{q}} \mathrm{q}_{\mathrm{t}-1}^{\mathrm{s}}+\varsigma^{\mathrm{q}_{\mathrm{t}}} \\
& \varsigma_{\mathrm{t}}^{\mathrm{q}} \sim \mathrm{N}\left(0, \mathrm{~h}_{\mathrm{t}}{ }^{\mathrm{q}}\right)
\end{aligned}
$$




$$
\mathrm{h}_{\mathrm{t}}^{\mathrm{q}}=\xi_{0}^{\mathrm{q}}+\xi_{1}^{\mathrm{q}}\left(\zeta_{\mathrm{t}-1}^{\mathrm{q}}\right)^{2}+v_{1}^{\mathrm{q}} \mathrm{h}_{\mathrm{t}-1}^{\mathrm{q}} .
$$

Since the price dividend ratio is postulated to be an AR(1) process, the process in (19) is

$\operatorname{GARCH}(1,1)$. Similarly, for the risky rates of return we postulated the econometric model

$$
\begin{aligned}
& \varrho_{\mathrm{t}}^{\mathrm{s}}=\kappa^{\varrho}+\mu^{\varrho} \mathrm{q}_{\mathrm{t}}{ }^{\mathrm{s}}+\varsigma^{\varrho_{\mathrm{t}}} \\
& \varsigma_{\mathrm{t}}^{\varrho} \sim \mathrm{N}\left(0, \mathrm{~h}_{\mathrm{t}}^{\varrho}\right) \\
& \mathrm{h}_{\mathrm{t}}^{\varrho}=\xi_{0}^{\varrho}+\xi_{1}^{\varrho}\left(\varsigma_{\mathrm{t}-1}^{\varrho}\right)^{2}+v_{1}^{\varrho} \mathrm{h}_{\mathrm{t}-1}^{\varrho} .
\end{aligned}
$$

For a specification of (19) and (20) we have also tested $\operatorname{ARCH}(1)$ and $\operatorname{GARCH}(2,1)$ but have concluded that the proposed GARCH(1,1) as in (19)-(20), describes best the behavior of the data over time. Due to the large sample we ignore standard error and report our model implies that the estimated model for the price-dividend ratio satisfies the $\operatorname{GARCH}(1,1)$ specification

$$
\begin{aligned}
& \mathrm{q}_{\mathrm{t}}{ }^{\mathrm{s}}=8.11907+0.69137 \mathrm{q}_{\mathrm{t}-1}^{\mathrm{s}}+\varsigma^{\mathrm{q}_{\mathrm{t}}} \\
& \mathrm{s}_{\mathrm{t}}^{\mathrm{q}} \sim \mathrm{N}\left(0, \mathrm{~h}_{\mathrm{t}}{ }^{\mathrm{q}}\right) \\
& \mathrm{h}_{\mathrm{t}}{ }^{\mathrm{q}}=3.85997+0.01634\left(\varsigma_{\mathrm{t}-1}^{\mathrm{q}}\right)^{2}+0.70539 \mathrm{~h}_{\mathrm{t}-1}^{\mathrm{q}}, \quad \mathrm{R}^{2}=0.477 .
\end{aligned}
$$

For the risky rates of return the estimated model satisfies the $\operatorname{GARCH}(1,1)$ specification

$$
\begin{aligned}
& \varrho_{\mathrm{t}}=-0.22024+0.01039 \mathrm{q}_{\mathrm{t}}{ }^{\mathrm{s}}+\varsigma_{\mathrm{t}}^{\varrho} \\
& \varsigma_{\mathrm{t}}^{\varrho} \sim \mathrm{N}\left(0, \mathrm{~h}_{\mathrm{t}}^{\varrho}\right) \\
& \mathrm{h}_{\mathrm{t}}^{\varrho}=0.00720+0.10914\left(\varsigma_{\mathrm{t}-1}^{\varrho}\right)^{2}+0.61160 \mathrm{~h}_{\mathrm{t}-1}^{\varrho}, \quad \mathrm{R}^{2}=0.111 .
\end{aligned}
$$

Stochastic volatility in our model is the direct consequence of the dynamics of the market state of beliefs $z_{t}=\left(z_{t}^{1}, z_{t}^{2}\right)$. To understand why note first that for any pattern of values which $\left(z_{t}^{1}, z_{t}^{2}\right)$ take, persistence of beliefs and correlation across agents cause the persistence of that pattern. When agents disagree (i.e. $z_{t}^{1} z_{t}^{2}<0$ ) they offset the demands of each other and as that pattern persists, prices do not need to change by much for markets to clear. In such periods prices exhibit low volatile and persistence of belief states induce persistence of low volatility. When agents agree (i.e. $z_{t}^{1} z_{t}^{2}>0$ ) they compete for the same assets and prices are determined by difference in intensity of their beliefs. Variations in the degree of the bull or bear states generate high volatility in asset prices and returns. Persistence of beliefs cause such high volatility regimes to exhibit persistence. Thus, the level of market volatility is time dependent. It changes with the market state of beliefs $z_{t}$ and hence it has a predictable component as in (19)-(20). From a formal perspective, this is an extension of a similar result in Kurz and Motolese (2001). 
The virtue of the above argument is that it explains the presence of stochastic volatility as an endogenous consequence of equilibrium dynamics. Some "fundamental" shocks (such as an oil shock) surely cause market volatility, but it has been empirically established that market volatility cannot be explained consistently by any repeated "fundamental" exogenous shocks (compare with Timmermann and Pesaran (1995)). Hence, our explanation of stochastic volatility is consistent with the empirical evidence and is compatible with our general paradigm which views market expectations as the primary cause of market volatility.

\section{Concluding Remarks}

This paper presents a unified paradigm proposing that market volatility is driven primarily by market expectations. This conclusion extends and supports our previous results (cited earlier) on the subject. We constructed a simple model and tested it on all aspects of market volatility and found the model to match well the empirical record. The structure of the model is applicable to any phenomenon associated with market volatility since our main results are qualitative rather than quantitative. These results are driven by the fact that, under the Rational Belief principle, we do not write down a formal belief formation model. For a general equilibrium formulation all we need is a quantitative measure of how forecasts of an agent deviate from the empirical forecast. This is accomplished via the main tool of this paper which is the individual and market states of belief. These are indexes identifying the distribution of conditional probability functions of the agents at each date. Using this tool we show that there are two simple forces through which beliefs drive volatility: (i) over confidence of an agent' forecasts described by amplification of the agent's probabilities which, in turn, generate densities with fat tails, and (ii) asymmetry in the frequency of bull or bear states. Although these principles can be satisfied by different belief formation models, the simplest way to think of them is as an expression of animal spirits.

The important role market states of belief play in our theory is reflected in the fact that agents hold diverse individual forecasts of future market states of belief when they write down their Euler equations. In a mathematical sense our model is then a fully developed general equilibrium structure within which Keynes' intuitive "Beauty Contest" aspect of asset pricing is formally well defined. However, on a deeper level heterogenous individual forecasts of future 
market states of belief is entirely equivalent to heterogenous forecasts of future asset prices and interest rates and heterogenous price forecasting is the essence of our theory. In a general equilibrium context the tool of a market state of belief is a formal method for allowing agents to be rational and use the same equilibrium map (5) yet make heterogenous price forecasts. This suggest that we could build models in which agents make heterogenous price forecasts but then it will be equivalent to a model in which they know the equilibrium map but make heterogenous forecasts of an object like the market state of beliefs.

\section{References}

Abel, A.B. (1990): "Asset Prices Under Habit Formation and Catching Up With the Joneses." American Economic Review (Papers and Proceedings), 80, 38 - 42.

Abel, A.B. (1999): "Risk Premia and Term Premia in General Equilibrium." Journal of Monetary Economics 43, 3 - 33.

Backus, D. K., Gregory, A.W., Zin, S.E. (1989): "Risk Premiums in the Term Structure: Evidence from Artificial Economies." Journal of Monetary Economics, 24, 371 - 399.

Barberis, N., Huang, M., Santos, T. (2001): "Prospect Theory and Asset Prices." Quarterly Journal of Economics, CXVI, 1-53.

Bollerslev, T., Engle, R., Nelson, D. (1994): "ARCH Models". In Engle, R., McFadden, G., (eds.) Handbook Of Econometrics, Vol. IV, Amsterdam: North Holland.

Breeden, D.T. (1979): "An Intertemporal Asset Pricing Model with Stochastic Consumption and Investment Opportunities." Journal of Financial Economics, 7, 265 - 296.

Brennan, M.J., Xia, Y. (1998): "Stock Price Volatility, Learning, and the Equity Premium.” UCLA, Anderson School, February.

Brock, W.A., LeBaron, B.D. (1996): "A Dynamic Structural Model for Stock Return Volatility and Trading Volume". The Review of Economics and Statistics 78 , 94 -110.

Campbell, J. Y. (2000): "Asset Prices, Consumption and the Business Cycle." Taylor, J. B., Woodford, M. (ed.) Handbook of Macroeconomics, Volume 1C, Chapter 19, 1231-1303.

Campbell, J.Y., Cochrane, J.H. (1999): "By Force of Habit: A Consumption-Based Explanation of Aggregate Stock Market Behavior." Journal of Political Economy, 107, 205 - 251.

Campbell, J. Y., Cochrane, J. H. (2000): "Explaining the Poor Performance of ConsumptionBased Asset Pricing Models." The Journal of Finance, 55, 2863-2878.

Campbell, J.Y., Shiller, R.J. (1988): "Stock Prices, Earnings, and Expected Dividends." Journal of Finance 43, 661-676.

Campbell, J. Y., Shiller, R. J. (1991): "Yield Spreads and Interest Rate Movements: A Bird's Eye View." Review of Economic Studies, 58, 495 - 514.

Camerer, C., Lovallo, D., (1999): "Overconfidence and Excess Entry: An Experimental Approach." American Economic Review, 89, 306 - 318.

Cecchetti, S., Lam, P., Mark, N. (1990): "Mean Reversion in Equilibrium Asset Prices." American Economic Review 80, 398 - 418. 
Cecchetti, S., Lam, P., Mark, N. (1993): "The Equity Premium and the Risk-Free Rate: Matching the Moments." Journal of Monetary Economics, 31, 21 - 45.

Constantinides, G. (1990) Habit Formation: A Resolution of the Equity Premium Puzzle. Journal of Political Economy 98, 519 - 543.

Engel, C. M. (1996): "The Forward Discount Anomaly and the Risk Premium: Survey of Recent Evidence." Journal of Empirical Finance, 3, 123 - 192.

Epstein, L.G., Zin, S.E. (1990): "First-Order" Risk Aversion and the Equity Premium Puzzle." Journal of Monetary Economics 26, 387 - 407.

Fama, E.F., French, K.R. (1988a): "Permanent and Temporary Components of Stock Prices." Journal of Political Economy 96, 246-273.

Fama, E.F., French, K.R. (1988b): "Dividend Yields and Expected Stock Returns." Journal of Financial Economics 22, 3-25.

Fan, M. (2003): "Evolving Term Structure with Heterogenous Beliefs." Manuscript, Department of Economics, Stanford University, August.

Froot, K.A., Frankel, J.A. (1989) : "Forward Discount Bias: Is it an Exchange Risk Premium?" Quarterly Journal of Economics 104, 139-161.

Grossman, S.J., Shiller, R. J. (1981): "The Determinants of the Variability of Stock Market Prices." American Economic Review (Papers and Proceedings) 71, 222 - 227.

Heaton, J., Lucas, D.J. (1996): "Evaluating the Effects of Incomplete Markets on Risk Sharing and Asset Pricing." Journal of Political Economy 104, 443-487.

Hansen, L.P., Singleton, K.L. (1983): "Stochastic Consumption, Risk Aversion, and the Temporal Behavior of Asset Returns." Journal of Political Economy, 91, 249 - 268.

Jin, H., Judd, K. (2002): " Perturbation Method for General Dynamic Stochastic Models." Stanford University, http://www.stanford.edu/group/site/judd.03.2.pdf

Jin, H. (2003): "PSD - A Perturbation Solver for Dynamic Systems." Stanford University, Department of Economics, http://www.stanford.edu/ jinhehui/psdman.pdf

Kahneman, D., Tversky, A. (1979), "Prospect Theory: An Analysis of Decision Under Risk." Econometrica, 47, 263 - 291.

Kocherlakota, N.R. (1996): "The Equity Premium: It's Still a Puzzle." Journal of Economic Literature, 34, 42 -71.

Kurz, M. (1994): "On the Structure and Diversity of Rational Beliefs." Economic Theory 4, pp. 877 - 900 . (An edited version appears as Chapter 2 of Kurz, M. (ed.).: 1997)

Kurz, M. (ed.) (1996): "Symposium: Rational Beliefs and Endogenous Uncertainty." Economic Theory, 8, 383 - 553.

Kurz, M. (ed) (1997): Endogenous Economic Fluctuations: Studies in the Theory of Rational Belief. Studies in Economic Theory, No. 6, Berlin and New York: Springer-Verlag.

Kurz, M., Beltratti, A. (1997): "The Equity Premium is no Puzzle." Chapter 11 in Kurz, M. (ed.) (1997) Endogenous Economic Fluctuations: Studies in the Theory of Rational Belief. Studies in Economic Theory, No. 6, Berlin and New York: Springer-Verlag, 283 -316.

Kurz, M., Schneider, M. (1996): "Coordination and Correlation in Markov Rational Belief Equilibria." Economic Theory 8, pp. 489.

Kurz, M., Motolese, M. (2001): "Endogenous Uncertainty and Market Volatility." Economic Theory, 17, 497 - 544. 
LeRoy, S. F. (1973): "Risk Aversion and the Martingale Property of Stock Prices." International Economic Review, 14, 436 - 446.

Lucas, R. E. Jr. (1978): "Asset Prices in an Exchange Economy." Econometrica, 46, 1429 1445.

Mankiw, G. N. (1986): "The Equity Premium and the Concentration of Aggregate Shocks." Journal of Monetary Economics, 15, 145 - 161.

Mehra, R., Prescott, E. C. (1985) : “The Equity Premium: A Puzzle.” Journal of Monetary Economics 15, 145-162.

Nielsen, K. C. (1996): "Rational Belief Structures and Rational Belief Equilibria. Economic Theory, 8, 339 - 422.

Poterba, J.M., Summers, L.H. (1988): "Mean Reversion in Stock Prices: Evidence and Implications." Journal of Financial Economics 22, 27-29.

Radner, R. (1972): "Existence of equilibrium of plans, prices and price expectations in a sequence of Markets." Econometrica 40, 289-303.

Reitz, T.A. (1988): "The Equity Premium: A Solution." Journal of Monetary Economics 22, $117-133$.

Rodriguez, J.C. (2002): "Consumption, the Persistence of Shocks, and Asset Pricing Puzzles." Draft, Department of Economics, University of Maryland.

Summers, L.H. (1986): “Does the Stock Market Rationally Reflect Fundamental Values?" Journal of Finance 41, 591-601.

Shiller, R. J. (1981): "Do Stock Prices Move Too Much to Be Justified by Subsequent Changes in Dividends." American Economic Review 71, 421 - 435.

Shilling, G. A. (1992): "Market Timing: Better Than Buy-and-Hold Strategy." Financial Analysis Journal, 48, 46 - 50.

Svenson, O., (1981): “Are We All Less Risky and More Skillful Than Our Fellow Drivers?” Acta Psychologica, 47, 143 - 148.

Timmermann, A. (1996): "Excess Volatility and Predictability of Stock Prices in Autoregressive Dividend Model with Learning." Review of Economic Studies, 63, 523 - 557.

Timmermann, A., Pesaran, H. (1995): "Predictability of Stock Returns: Robustness and Economic Significance." Journal of Finance, 50, 1201-1228.

Timmermann, A., Paye, B. (2003): "Instability of Return Prediction Models." Mimeo, UCSD.

Weil, P. (1989): "The Equity Premium Puzzle and the Riskfree Rate Puzzle." Journal of Monetary Economics, 24, 401 - 422.

Wu, H. W., W.C. Guo (2003): "Speculative Trading with Rational Belief and Endogenous Uncertainty." Economic Theory 21, 263 - 292.

Wu, H. W., W.C. Guo (2004): "Asset Price Volatility and Trading Volume with Rational Beliefs." Economic Theory (forthcoming). 


\section{Appendix A: construction of the random variables $\rho_{t+1}^{j}\left(u_{t}^{j}\right)$}

Let $\phi\left(u_{t}^{j}\right)=\frac{1}{b\left(u_{t}^{j}-a\right)}$. This function is aimed at representing how agents deviate from the stationary forecast. Agents pick the frequency parameter a and the intensity parameter $b$. Given that we can carry out computations only with standard normal variables we need to normalize the variable $u$ :

$$
\phi\left(u_{t}^{j}\right)=\frac{1}{1+e^{b\left(u_{t}^{j}-a\right)}}=\phi\left(\tilde{u}_{t}^{j}\right)=\frac{1}{1+e^{\bar{b}\left(\tilde{u}_{t}^{j}-\bar{a}\right)}}
$$

where $\bar{b}=b \sigma_{u_{t}^{j}}, \bar{a}=a / \sigma_{u_{t}^{j}}$ and $\tilde{u}_{t}^{j} \sim N(0,1)$.

\section{A.1 The density function}

The density function of $\rho_{t+1}^{j}\left(\tilde{u}_{t}^{j}\right)$, conditioning on $\tilde{u}_{t}^{j}$ is given by:

$$
p\left(\rho_{t+1}^{j} \mid \tilde{u}_{t}^{j}\right)=\left\{\begin{array}{lll}
\phi_{1}\left(\tilde{u}_{t}^{j}\right) \Phi\left(\rho_{t+1}^{j}\right) & \text { if } \rho_{t+1}^{j} \geq 0 \\
\phi_{2}\left(\tilde{u}_{t}^{j}\right) \Phi\left(\rho_{t+1}^{j}\right) & \text { if } \rho_{t+1}^{j}<0
\end{array}\right.
$$

where

$$
\Phi\left(\rho_{\mathrm{t}+1}^{\mathrm{j}}\right)=\frac{1}{\sqrt{2 \pi}} \mathrm{e}^{-\frac{\left(\rho_{\mathrm{t}+1}^{\mathrm{j}}\right)^{2}}{2}}
$$

is the standard normal density function and

$$
\phi_{2}\left(\tilde{\mathrm{u}}_{\mathrm{t}}^{\mathrm{j}}\right)=\frac{\phi\left(\tilde{\mathrm{u}}_{\mathrm{t}}^{\mathrm{j}}\right)}{\mathrm{G}}, \quad \phi_{1}\left(\tilde{\mathrm{u}}_{\mathrm{t}}^{\mathrm{j}}\right)=2-\phi_{2}\left(\tilde{\mathrm{u}}_{\mathrm{t}}^{\mathrm{j}}\right), \quad \mathrm{G}=\int_{-\infty}^{\infty} \phi\left(\tilde{\mathrm{u}}_{\mathrm{t}}^{\mathrm{j}}\right) \frac{1}{\sqrt{2 \pi}} \mathrm{e}^{\frac{\left(\mathrm{u}_{\mathrm{t}}^{\mathrm{j}}\right)^{2}}{2}} \mathrm{~d} \tilde{\mathrm{u}}_{\mathrm{t}}^{\mathrm{j}}
$$

Note that $\mathrm{E} \phi_{1}\left(\tilde{\mathrm{u}}_{\mathrm{t}}^{\mathrm{j}}\right)=\mathrm{E} \phi_{2}\left(\tilde{\mathrm{u}}_{\mathrm{t}}^{\mathrm{j}}\right)=1$, which ensures that the rationality conditions be satisfied, i.e.:

$$
\int_{-\infty}^{\infty} p\left(\rho_{t+1}^{j} \mid \tilde{u}_{t}^{j}\right) p\left(\tilde{u}_{t}^{j}\right) d \tilde{u}_{t}^{j}=\Phi\left(\rho_{t+1}^{j}\right)
$$

We need another condition to make sure $p\left(\rho_{t+1}^{j} \mid \tilde{u}\right)$ is a density function for all $\tilde{u}_{t}^{j}$. This requires $\phi_{1}\left(\tilde{\mathrm{u}}_{\mathrm{t}}^{\mathrm{j}}\right) \geq 0$ for all $\tilde{\mathrm{u}}_{\mathrm{t}}^{\mathrm{j}}$, which implies $\mathrm{G} \geq 1 / 2$. 
A.2 The moments of $\rho_{t+1}^{j}\left(\tilde{u}_{t}^{j}\right)$

$$
\begin{aligned}
& E\left[\rho_{t+1}^{j} \mid \tilde{u}_{t}^{j}\right]=\frac{\phi_{1}\left(\tilde{u}_{t}^{j}\right)}{\sqrt{2 \pi}} \int_{0}^{\infty} x e^{-\frac{x^{2}}{2}} d x+\frac{\phi_{2}\left(\tilde{u}_{t}^{j}\right)}{\sqrt{2 \pi}} \int_{-\infty}^{0} x e^{-\frac{x^{2}}{2}} d x \\
& =\frac{\phi_{1}\left(\tilde{\mathrm{u}}_{\mathrm{t}}^{\mathrm{j}}\right)}{\sqrt{2 \pi}} \int_{0}^{\infty} \mathrm{d}\left(-\mathrm{e}^{-\frac{\mathrm{x}^{2}}{2}}\right)+\frac{\phi_{2}\left(\tilde{\mathrm{u}}_{\mathrm{t}}^{\mathrm{j}}\right)}{\sqrt{2 \pi}} \int_{-\infty}^{0} \mathrm{~d}\left(-\mathrm{e}^{-\frac{\mathrm{x}^{2}}{2}}\right) \\
& =\frac{\phi_{1}\left(\tilde{\mathrm{u}}_{\mathrm{t}}^{\mathrm{j}}\right)-\phi_{2}\left(\tilde{\mathrm{u}}_{\mathrm{t}}^{\mathrm{j}}\right)}{\sqrt{2 \pi}} \\
& =\left(1-\frac{\phi\left(\tilde{\mathrm{u}}_{\mathrm{t}}^{\mathrm{j}}\right)}{\mathrm{G}}\right) \frac{2}{\sqrt{2 \pi}} \\
& \mathrm{E}\left[\left(\rho_{\mathrm{t}+1}^{\mathrm{j}}\right)^{2} \mid \tilde{\mathrm{u}}_{\mathrm{t}}^{\mathrm{j}}\right]=\frac{\phi_{1}\left(\tilde{\mathrm{u}}_{\mathrm{t}}^{\mathrm{j}}\right)}{\sqrt{2 \pi}} \int_{0}^{\infty} \mathrm{x}^{2} \mathrm{e}^{-\frac{\mathrm{x}^{2}}{2}} \mathrm{dx}+\frac{\phi_{2}\left(\tilde{\mathrm{u}}_{\mathrm{t}}^{\mathrm{j}}\right)}{\sqrt{2 \pi}} \int_{-\infty}^{0} \mathrm{x}^{2} \mathrm{e}^{-\frac{\mathrm{x}^{2}}{2}} \mathrm{dx} \\
& =\frac{\phi_{1}\left(\tilde{\mathrm{u}}_{\mathrm{t}}^{\mathrm{j}}\right)}{\sqrt{2 \pi}} \int_{0}^{\infty} \mathrm{xd}\left(-\mathrm{e}^{-\frac{\mathrm{x}^{2}}{2}}\right)+\frac{\phi_{2}\left(\tilde{\mathrm{u}}_{\mathrm{t}}^{\mathrm{j}}\right)}{\sqrt{2 \pi}} \int_{-\infty}^{0} \mathrm{xd}\left(-\mathrm{e}^{-\frac{\mathrm{x}^{2}}{2}}\right) \\
& =\phi_{1}\left(\tilde{\mathrm{u}}_{\mathrm{t}}^{\mathrm{j}}\right) 0.5+\phi_{2}\left(\tilde{\mathrm{u}}_{\mathrm{t}}^{\mathrm{j}}\right) 0.5 \\
& =1 \\
& \mathrm{E}\left[\left(\rho_{\mathrm{t}+1}^{\mathrm{j}}\right)^{3} \mid \tilde{\mathrm{u}}_{\mathrm{t}}^{\mathrm{j}}\right]=\frac{\phi_{1}\left(\tilde{\mathrm{u}}_{\mathrm{t}}^{\mathrm{j}}\right)}{\sqrt{2 \pi}} \int_{0}^{\infty} \mathrm{x}^{3} \mathrm{e}^{-\frac{\mathrm{x}^{2}}{2}} \mathrm{dx}+\frac{\phi_{2}\left(\tilde{\mathrm{u}}_{\mathrm{t}}^{\mathrm{j}}\right)}{\sqrt{2 \pi}} \int_{-\infty}^{0} \mathrm{x}^{3} \mathrm{e}^{-\frac{\mathrm{x}^{2}}{2}} \mathrm{dx} \\
& =\frac{\phi_{1}\left(\tilde{\mathrm{u}}_{\mathrm{t}}^{\mathrm{j}}\right)}{\sqrt{2 \pi}} \int_{0}^{\infty} \mathrm{x}^{2} \mathrm{~d}\left(-\mathrm{e}^{-\frac{\mathrm{x}^{2}}{2}}\right)+\frac{\phi_{2}\left(\tilde{\mathrm{u}}_{\mathrm{t}}^{\mathrm{j}}\right)}{\sqrt{2 \pi}} \int_{-\infty}^{0} \mathrm{x}^{2} \mathrm{~d}\left(-\mathrm{e}^{-\frac{\mathrm{x}^{2}}{2}}\right) \\
& =\frac{\phi_{1}\left(\tilde{\mathrm{u}}_{\mathrm{t}}^{\mathrm{j}}\right)}{\sqrt{2 \pi}} 2 \int_{0}^{\infty} \mathrm{xe}^{-\frac{\mathrm{x}^{2}}{2}} \mathrm{dx}+\frac{\phi_{2}\left(\tilde{\mathrm{u}}_{\mathrm{t}}^{\mathrm{j}}\right)}{\sqrt{2 \pi}} 2 \int_{-\infty}^{0} \mathrm{xe}^{-\frac{\mathrm{x}^{2}}{2}} \mathrm{dx} \\
& =2 \mathrm{E}\left[\rho_{\mathrm{t}+1}^{\mathrm{j}} \tilde{\mathrm{u}}_{\mathrm{t}}^{\mathrm{j}}\right]=\left(1-\frac{\phi\left(\tilde{\mathrm{u}}_{\mathrm{t}}^{\mathrm{j}}\right)}{\mathrm{G}}\right) \frac{4}{\sqrt{2 \pi}}
\end{aligned}
$$

Since $\mathrm{E} \phi_{1}=\mathrm{E} \phi_{2}=1$ and $\mathrm{E} \tilde{\mathrm{u}}_{\mathrm{t}}^{\mathrm{j}}=0$, we have $\mathrm{E}\left[\rho_{\mathrm{t}+1}^{\mathrm{j}}\right]=0, \mathrm{E}\left[\left(\rho_{\mathrm{t}+1}^{\mathrm{j}}\right)^{2}\right]=1$ and $E\left[\rho_{t+1}^{j} \tilde{u}_{t}^{j}\right]=\frac{2}{\sqrt{2 \pi}} \frac{E\left[\phi\left(\tilde{u}_{t}^{j}\right) \tilde{u}_{t}^{j}\right]}{G}$. We can now reformulate the random variable $\rho_{t+1}^{j}\left(u_{t}^{j}\right)$ as used in the computational model. Let 


$$
\begin{aligned}
\mu\left(\tilde{u}_{t}^{j}\right) & \equiv E\left[\rho_{t+1}^{j} \mid \tilde{u}_{t}^{j}\right] \\
s\left(\tilde{u}_{t}^{j}\right) & \equiv \sqrt{E\left[\left(\rho_{t+1}^{j}\right)^{2} \mid \tilde{u}_{t}^{j}\right]-\left(E\left[\rho_{t+1}^{j} \mid \tilde{u}_{t}^{j}\right]\right)^{2}} \\
v_{t+1}^{j} & \equiv \frac{\rho_{t+1}^{j}-\mu\left(\tilde{u}_{t}^{j}\right)}{s\left(\tilde{u}_{t}^{j}\right)}
\end{aligned}
$$

and define $\quad \hat{\rho}_{t+1}^{j}\left(\tilde{u}_{t}^{j}\right)=\mu\left(\tilde{u}_{t}^{j}\right)+s\left(\tilde{u}_{t}^{j}\right) v_{t+1}^{j} \quad$ where

$$
\mu\left(\tilde{\mathrm{u}}_{\mathrm{t}}^{\mathrm{j}}\right)=\left(1-\frac{\phi\left(\tilde{\mathrm{u}}_{\mathrm{t}}^{\mathrm{j}}\right)}{\mathrm{G}}\right) \frac{2}{\sqrt{2 \pi}} \text { and } \mathrm{s}\left(\left(_{\mathrm{u}}^{\mathrm{u}} \mathrm{t}_{\mathrm{t}}^{\mathrm{j}}\right)=\sqrt{1-\mu\left(\tilde{\mathrm{u}}_{\mathrm{t}}^{\mathrm{j}}\right)^{2}} .\right.
$$

\section{Appendix B: Statement of the Rationality Conditions}

The rationality of belief principle requires that

(B1) $\Psi_{t+1}\left(u_{t}^{j}\right)=\left(\begin{array}{c}\lambda_{y}^{x} \rho_{t+1}^{j}\left(u_{t}^{j}\right)+\tilde{\rho}_{t+1}^{x^{j}} \\ \lambda_{y}^{z^{1}} \rho_{t+1}^{j}\left(u_{t}^{j}\right)+\tilde{\rho}_{t+1}^{z^{j 1}} \\ \lambda_{y}^{z^{2}} \rho_{t+1}^{j}\left(u_{t}^{j}\right)+\tilde{\rho}_{t+1}^{z^{j 2}}\end{array}\right)$ has the same joint empirical distribution as $\rho_{t+1}=\left(\begin{array}{c}\rho_{t+1}^{x} \\ \rho_{t+1}^{z^{1}} \\ \rho_{t+1}^{z^{2}}\end{array}\right)$.

To clarify the mathematical development below it is useful to keep in mind the consistency conditions between $y^{j}$ and $z^{j}$. These conditions require that the realizations of the two are the same and hence they have the same marginal empirical distribution. This does not mean we require the covariance between $y^{j}$ and any state variable to be the same as the covariance implied by the system (6) between $z^{j}$ and that variable. Indeed, the presence of $\rho_{t+1}^{j}\left(u_{t}^{j}\right)$ in all equations of the perception model (15) generates covariance between $y^{j}$ and other state variables which is not present in (6). The idea is that any covariance between an agent's own state of belief and other variables in the economy are strictly in the mind of the agent and no rationality conditions are imposed on them. A striking way to see this is to note that under the condition of anonymity an agent sees no relationship between his own state of belief and the market belief. We then assume that in the subjective perception model $\operatorname{Cov}\left(\mathrm{y}^{\mathrm{j}}, \mathrm{z}^{\mathrm{i}}\right)=0$.

We now show that (B1) fully specify the covariance matrix $\Sigma_{\rho \rho}$ of the three dimensional vector $\tilde{\rho}_{\mathrm{t}+1}^{\mathrm{j}}$ in the perception models (15)-(16). To see this rewrite (11a) in the form 


$$
w_{t+1}^{j}=A w_{t}+\lambda_{y} \rho_{t+1}^{j}\left(u_{t}^{j}\right)+\tilde{\rho}_{t+1}^{j}
$$

Now define $\sigma_{\rho}^{2}=E\left[\left(\rho_{t+1}^{j}\left(u_{t}^{j}\right)\right)^{2}\right]$ and denote by $V$ be the covariance matrix of the random vector $\mathrm{w}_{\mathrm{t}}$ as derived from (8). Computing now the covariance matrix in we see that for these two to be equal we must have the equality $\mathrm{V}=\mathrm{AVA}^{\prime}+\lambda_{\mathrm{y}} \mathrm{j}\left(\lambda_{\mathrm{y}}\right)^{\prime} \sigma_{\rho}^{2}+\Sigma_{\rho \rho}$ which means that

$$
\Sigma_{\rho \rho}=\mathrm{V}-\mathrm{AVA}^{\prime}-\lambda_{\mathrm{y}}\left(\lambda_{\mathrm{y}}\right)^{\prime} \sigma_{\rho}^{2}
$$

Given parameters $\left(\mathrm{a}, \mathrm{b}, \lambda_{\mathrm{y}} \mathrm{j}\right)$ all magnitudes on the right of (B2) are known and this pins down the covariance matrix $\Sigma_{\rho \rho}$. Since perception models include (9), the covariance $\Omega$ of the innovations is specified when $r_{j} \equiv \operatorname{Cov}\left(w, y^{j}\right)$ is known. We now show that these are pinned down by the condition of no serial correlation of $\Psi_{t+1}\left(u_{t}{ }^{j}\right)$.

For $\Psi_{t+1}\left(u_{t}^{j}\right)$ to exhibit no serial correlation it is sufficient that it is uncorrelated with date $t$ public information. To see why recall that $\Psi_{t+1}\left(u_{t}^{j}\right)=w_{t+1}-A w_{t}$ hence $\mathrm{E}\left[\Psi_{\mathrm{t}+1}\left(\mathrm{u}_{\mathrm{t}}^{\mathrm{j}}\right) \Psi_{\mathrm{t}}\left(\mathrm{u}_{\mathrm{t}-1}^{\mathrm{j}}\right)\right]=\mathrm{E}\left[\Psi_{\mathrm{t}+1}\left(\mathrm{u}_{\mathrm{t}}^{\mathrm{j}}\right)\left(\mathrm{w}_{\mathrm{t}}-\mathrm{Aw}_{\mathrm{t}-1}\right]=\mathrm{E}\left[\Psi_{\mathrm{t}+1}\left(\mathrm{u}_{\mathrm{t}}^{\mathrm{j}}\right)\left(\mathrm{w}_{\mathrm{t}}\right)\right]-\mathrm{E}\left[\Psi_{\mathrm{t}+1}\left(\mathrm{u}_{\mathrm{t}}^{\mathrm{j}}\right) A \mathrm{w}_{\mathrm{t}-1}\right]=0\right.$. To ensure the above we seek conditions on $r_{j}$ to ensure $u_{t}^{j}$ are not correlated with any $w_{t-i}^{j}$ all $i$. We denote by $a_{j}=\left(\lambda_{x}^{z^{j}}, 0,0\right)$ the vector of $w$ parameters in the $y^{j}$ equation (9). Then $\mathrm{u}\left(\mathrm{y}_{\mathrm{t}+1}^{\mathrm{j}}\right)=\mathrm{y}_{\mathrm{t}+1}^{\mathrm{j}}-\mathrm{r}_{\mathrm{j}} \mathrm{V}^{-1} \mathrm{w}_{\mathrm{t}+1}=\lambda_{\mathrm{z}} \mathrm{y}_{\mathrm{t}}^{\mathrm{j}}+\mathrm{a}_{\mathrm{j}}{ }^{\prime} \mathrm{w}_{\mathrm{t}}+\tilde{\rho}_{\mathrm{t}+1}^{\mathrm{y}^{\mathrm{j}}}-\mathrm{r}_{\mathrm{j}}{ }^{\prime} \mathrm{V}^{-1}\left(A \mathrm{w}_{\mathrm{t}}+\lambda_{\mathrm{y}} \mathrm{\rho}_{\mathrm{t}+1}^{\mathrm{j}}\left(\mathrm{u}_{\mathrm{t}}\right)+\tilde{\rho}_{\mathrm{t}+1}^{\mathrm{j}}\right)$. The condition $\operatorname{Cov}\left(\mathrm{u}_{\mathrm{t}+1}^{\mathrm{j}}, \mathrm{w}_{\mathrm{t}}\right) \equiv \mathrm{E}\left[\mathrm{u}_{\mathrm{t}+1}^{\mathrm{j}}, \mathrm{w}_{\mathrm{t}}{ }^{\prime}\right]=0$ requires $\lambda_{\mathrm{z}}{ }_{\mathrm{j}} \mathrm{r}^{\prime}+\mathrm{a}_{\mathrm{j}}{ }^{\prime} \mathrm{V}-\mathrm{r}_{\mathrm{j}}{ }^{\prime} \mathrm{V}^{-1} \mathrm{AV}=0$ hence the covariance vector $r_{j}$ is determined by the equation

$$
\left[\mathrm{A}^{\prime}-\lambda_{\mathrm{z}} \mathrm{I}\right] \mathrm{V}^{-1} \mathrm{r}_{\mathrm{j}}{ }^{\prime}=\mathrm{a}_{\mathrm{j}}
$$

We study here only the symmetric case $\lambda_{\mathrm{z}^{1}}=\lambda_{\mathrm{z}^{2}}=\lambda_{\mathrm{z}}$. In this case we have that

$$
\mathrm{A}^{\prime}=\left(\begin{array}{ccc}
\lambda_{\mathrm{x}}, & \lambda_{\mathrm{x}}^{\mathrm{z}_{1}}, \lambda_{\mathrm{x}}^{\mathrm{z}_{2}} \\
0, & \lambda_{\mathrm{z}}, 0 \\
0, & 0, \lambda_{\mathrm{z}}
\end{array}\right)
$$

hence the matrix $\left[\mathrm{A}^{\prime}-\lambda_{\mathrm{z}} \mathrm{I}\right]$ is singular with the last two rows being zero. This is compatible with the fact that $a_{j}=\left(\lambda_{x}^{z}, 0,0\right)$ hence, only one components of $r_{j}$ matters. In accord with anonymity 
we set $\operatorname{Cov}\left(z^{1}, y^{j}\right)=\operatorname{Cov}\left(z^{2}, y^{j}\right)=0$ and (B3) determines $r_{j}$. Finally, when $r_{j}$ is known, $\tilde{\sigma}_{y}^{2}$ is pinned down as follows. Since we know that $\sigma_{u}^{2}{ }^{j}=\operatorname{var}\left(y^{j}\right)-r_{j}{ }^{\prime} V^{-1} r_{j}$, we can compute $\tilde{\sigma}_{y}^{2}=\left(1-\lambda_{z^{j}}^{2}\right) \operatorname{var}\left(y^{j}\right)-a_{j}{ }^{\prime} V a_{j}-2 \lambda_{z^{j}} a_{j}{ }^{\prime} r_{j}$ using the condition $\operatorname{var}\left(y^{j}\right)=\operatorname{var}\left(z^{j}\right)$.

\section{Appendix C: the computational model}

This appendix explores several computational issues which have not been discussed in the text. We want to provide here a complete description of the computed equilibrium conditions.

\section{C.1 Equilibrium set and indeterminacy in the riskless economy}

To ensure the existence of bounded solutions and hence exclude explosive solutions which violate transversality we impose quadratic utility penalties on deviation of asset holdings away from steady state. The penalty functions are: $D_{t}^{1-\gamma} \frac{\tau_{s}}{2}\left(\theta_{t}^{j}-0.5\right)^{2}$ for stock holdings and $D_{t}{ }^{-1-\gamma} \frac{\tau_{B}}{2}\left(B_{t}{ }^{j}\right)^{2}$ for bond holdings with $\tau_{\mathrm{s}}=\tau_{\mathrm{B}}=0.005$. The penalty functions are then subtracted from utility.

Indeterminacy of the optimal portfolio allocation at the riskless steady state is also a problem for perturbation models with a number of financial assets greater or equal to two. This is due to the fact that financial assets exhibit the same rate of return in the riskless economy and work as perfect substitutes. The penalty functions also insure that the steady state solution $\theta_{t}^{j}=0.5$ and $\mathrm{B}_{\mathrm{t}}^{\mathrm{j}}=0$ is unique.

\section{C.2 The revised optimization problem and the system of Euler equations}

Given the above, the optimization problem of agent $\mathrm{j}$ is then reformulated as follows:

$$
\underset{\left(C^{j}, \theta^{j}, B^{j}\right)}{\operatorname{Max}} E_{Q^{j}}\left[\sum_{t=0}^{\infty} \beta^{t} \frac{1}{1-\gamma}\left(C_{t}^{j}\right)^{1-\gamma}-D_{t}^{1-\gamma} \frac{\tau}{2}\left(\theta_{t}^{j}-0.5\right)^{2}-D_{t}^{-1-\gamma} \frac{\tau_{B}}{2}\left(B_{t}^{j}\right)^{2} \mid H_{t}\right]
$$

subject to:

$$
\mathrm{C}_{\mathrm{t}}^{\mathrm{j}}+\tilde{\mathrm{q}}_{\mathrm{t}}^{\mathrm{s}} \theta_{\mathrm{t}}^{\mathrm{j}}+\mathrm{q}_{\mathrm{t}}^{\mathrm{b}} \mathrm{B}_{\mathrm{t}}^{\mathrm{j}}=\Lambda_{\mathrm{t}}^{\mathrm{j}}+\left(\tilde{\mathrm{q}}_{\mathrm{t}}^{\mathrm{s}}+\mathrm{D}_{\mathrm{t}}\right) \theta_{\mathrm{t}-1}^{\mathrm{j}}+\mathrm{B}_{\mathrm{t}-1}^{\mathrm{j}}
$$

The Euler equations are:

$$
\begin{aligned}
& \left(C_{t}^{j}\right)^{-\gamma} \tilde{q}_{t}^{s}+D_{t}^{1-\gamma} \tau_{s}\left(\theta_{t}^{j}-0.5\right)=\beta E_{Q_{t}^{j}}\left[\left(C_{t+1}^{j}\right)^{-\gamma}\left(\tilde{q}_{t+1}^{s}+D_{t+1}\right) \mid H_{t}\right] \\
& \left(C_{t}^{j}\right)^{-\gamma} q_{t}^{b}+D_{t}{ }^{-\gamma-1} \tau_{B}\left(B_{t}^{j}\right)=\beta E_{Q_{t}^{j}}\left[\left(C_{t+1}^{j}\right)^{-\gamma} \mid H_{t}\right]
\end{aligned}
$$


After normalization the budget constraint becomes:

$$
c_{t}^{j}+q_{t}^{s} \theta_{t}^{j}+q_{t} b_{t} b^{j}=\omega+\left(q_{t}^{s}+1\right) \theta_{t-1}^{j}+b_{t-1}^{j} e^{-x_{t}}
$$

and the Euler equations become:

$$
\begin{aligned}
& \left(c_{t}{ }^{j}\right)^{-\gamma} q_{t}{ }^{s}+\tau_{s}\left(\theta_{t}^{j}-0.5\right)=\beta E_{Q_{t}^{j}}\left[\left(c_{t+1}^{j}\right)^{-\gamma}\left(1+q_{t+1}^{s}\right) e^{(1-\gamma) x_{t+1}} \mid H_{t}\right] \\
& \left(c_{t}\right)^{j}{ }^{-\gamma} q_{t}{ }^{b}+\tau_{b}\left(b_{t}^{j}\right)=\beta E_{Q_{t}^{j}}\left[\left(c_{t+1}^{j}\right)^{-\gamma} e^{-\gamma x_{t+1}} \mid H_{t}\right]
\end{aligned}
$$

\section{C.3 The riskless steady state}

In the riskless steady state quantities are as follows:

$$
\mathrm{b}^{1 *}=\mathrm{b}^{2 *}=0, \quad \theta^{1 *}=\theta^{2 *}=0.5, \quad \mathrm{c}^{1 *}=\mathrm{c}^{2 *}=\omega+0.5 .
$$

And prices are:

$$
\mathrm{q}^{\mathrm{s}}=\frac{\beta \mathrm{e}^{\mathrm{x}^{*}(1-\gamma)}}{1-\beta \mathrm{e}^{\mathrm{x}^{*}(1-\gamma)}}, \quad \mathrm{q}^{\mathrm{b}}=\beta \mathrm{e}^{-\gamma \mathrm{x}^{*}}
$$

\section{C.4 The perturbation structure}

We specify here how we formulated the perturbation model. Let $\varepsilon$ be the perturbation variable then the perturbation structure of the agent's perception model is as follows:

$$
\begin{aligned}
& \mathrm{x}_{\mathrm{t}+1}^{\mathrm{j}}=\left(1-\lambda_{\mathrm{x}}\right) \mathrm{x}^{*}+\lambda_{\mathrm{x}} \mathrm{x}_{\mathrm{t}}+\lambda_{\mathrm{y}}^{\mathrm{x}} \hat{\rho}_{\mathrm{t}+1}^{\mathrm{j}}\left(\tilde{\mathrm{u}}_{\mathrm{t}}^{\mathrm{j}}, \varepsilon\right)+\varepsilon \tilde{\rho}_{\mathrm{t}+1}^{\mathrm{j}} \\
& \mathrm{z}_{\mathrm{t}+1}^{\mathrm{j} 1}=\lambda_{\mathrm{z}} \mathrm{z}_{\mathrm{t}}^{1}+\lambda_{\mathrm{x}}^{\mathrm{z}}\left(\mathrm{x}_{\mathrm{t}}-\mathrm{x}^{*}\right)+\lambda_{\mathrm{y}}^{\mathrm{z}} \hat{\rho}_{\mathrm{t}+1}^{\mathrm{j}}\left(\tilde{\mathrm{u}}_{\mathrm{t}}^{\mathrm{j}}, \varepsilon\right)+\varepsilon \tilde{\rho}_{\mathrm{t}+1}^{\mathrm{z}^{\mathrm{j} 1}} \\
& \mathrm{z}_{\mathrm{t}+1}^{\mathrm{j} 2}=\lambda_{\mathrm{z}} \mathrm{z}_{\mathrm{t}}^{2}+\lambda_{\mathrm{x}}^{\mathrm{z}}\left(\mathrm{x}_{\mathrm{t}}-\mathrm{x}^{*}\right)+\lambda_{\mathrm{y}}^{\mathrm{z}} \hat{\rho}_{\mathrm{t}+1}^{\mathrm{j}}\left(\tilde{\mathrm{u}}_{\mathrm{t}}^{\mathrm{j}}, \varepsilon\right)+\varepsilon \tilde{\rho}_{\mathrm{t}+1}^{\mathrm{z}^{\mathrm{j} 2}} \\
& \mathrm{y}_{\mathrm{t}+1}^{\mathrm{j}}=\lambda_{\mathrm{z}} \mathrm{y}_{\mathrm{t}}^{\mathrm{j}}+\lambda_{\mathrm{x}}^{\mathrm{z}}\left(\mathrm{x}_{\mathrm{t}}-\mathrm{x}^{*}\right)+\varepsilon \tilde{\rho}_{\mathrm{t}+1}^{\mathrm{y}}
\end{aligned}
$$

where $\hat{\rho}_{t+1}^{j}\left(\tilde{u}_{t}^{j}, \varepsilon\right)=\mu\left(\tilde{u}_{t}^{j}\right)+\varepsilon s\left(\tilde{u}_{t}^{j}\right) v_{t+1}^{j}$ as defined in Appendix A. 

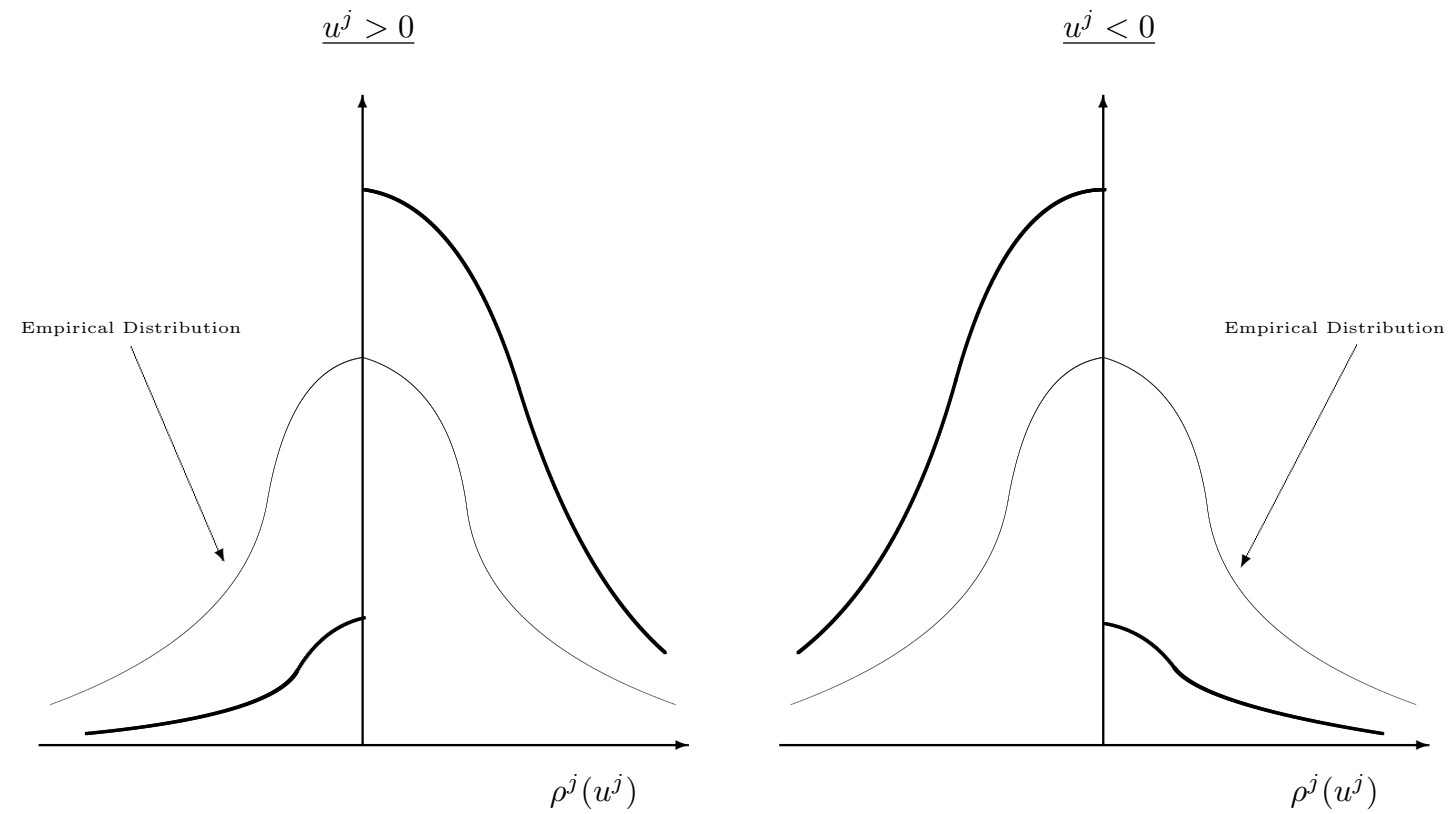

Figure 1: Non-Normal Belief Densities.

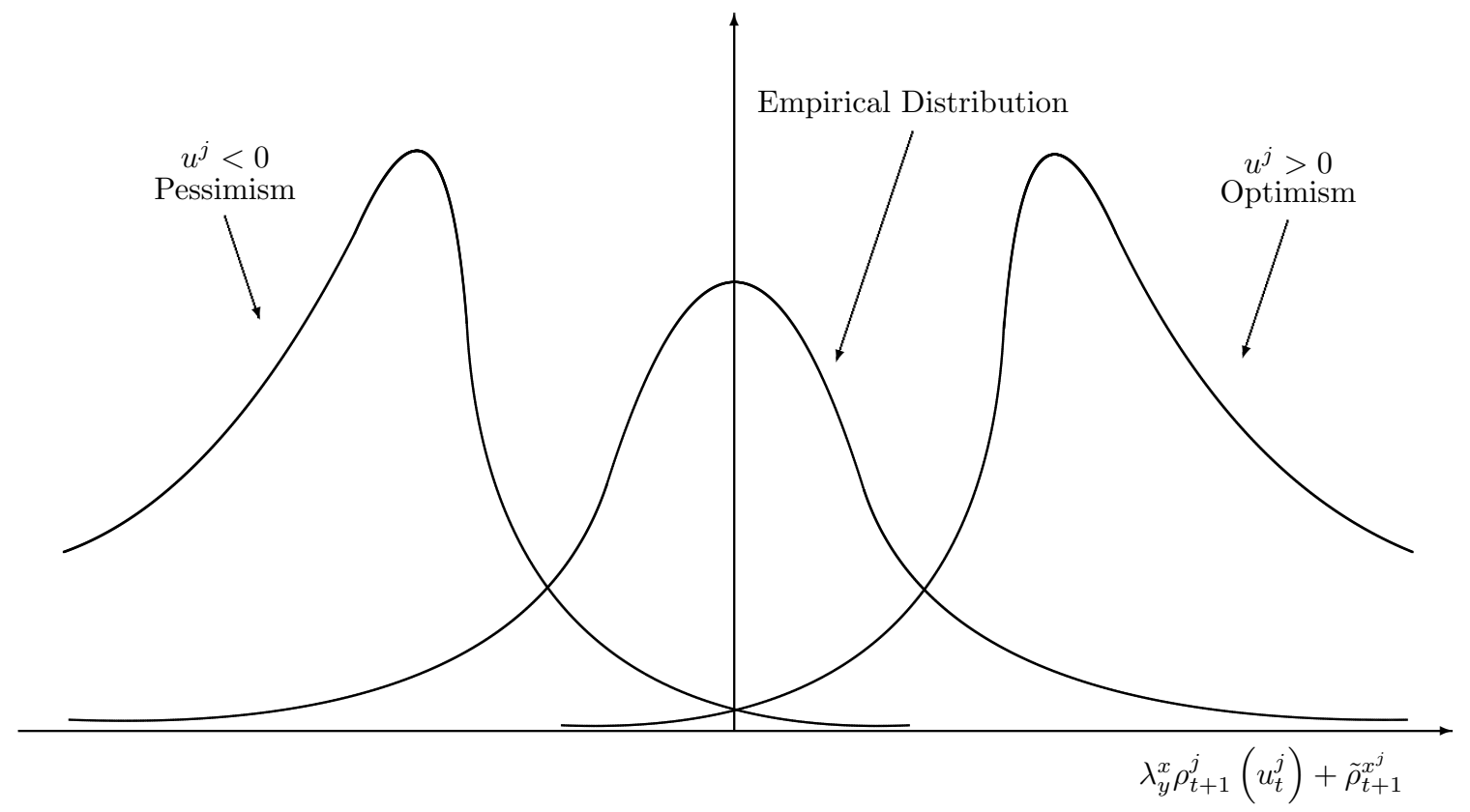

Figure 2: Density of $\Psi\left(u_{t}^{j}\right)$ with Fat Tails. 


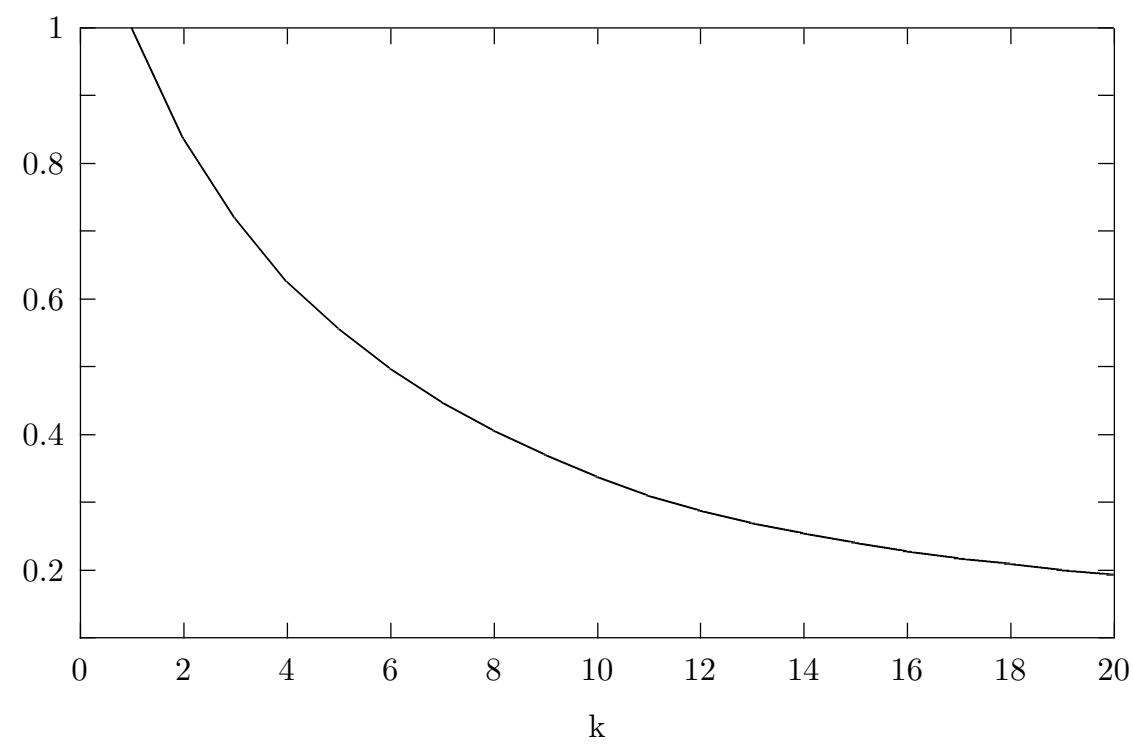

Figure 3: Variance Ratios.

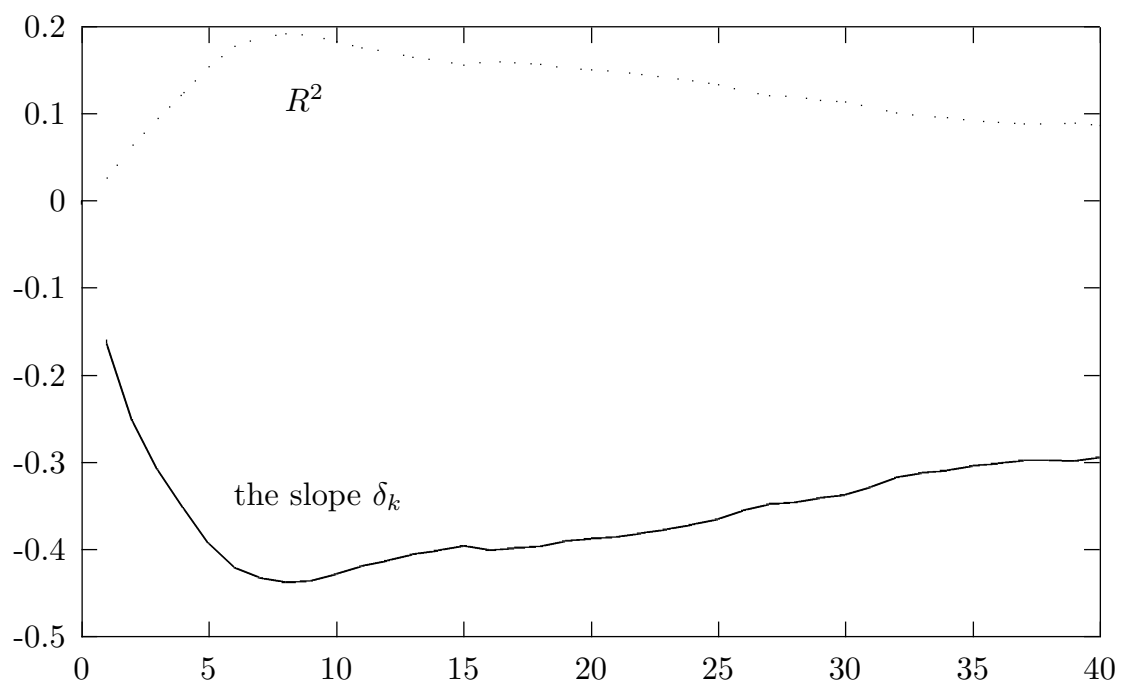

Figure 4: Properties of Returns from Regression (17). 


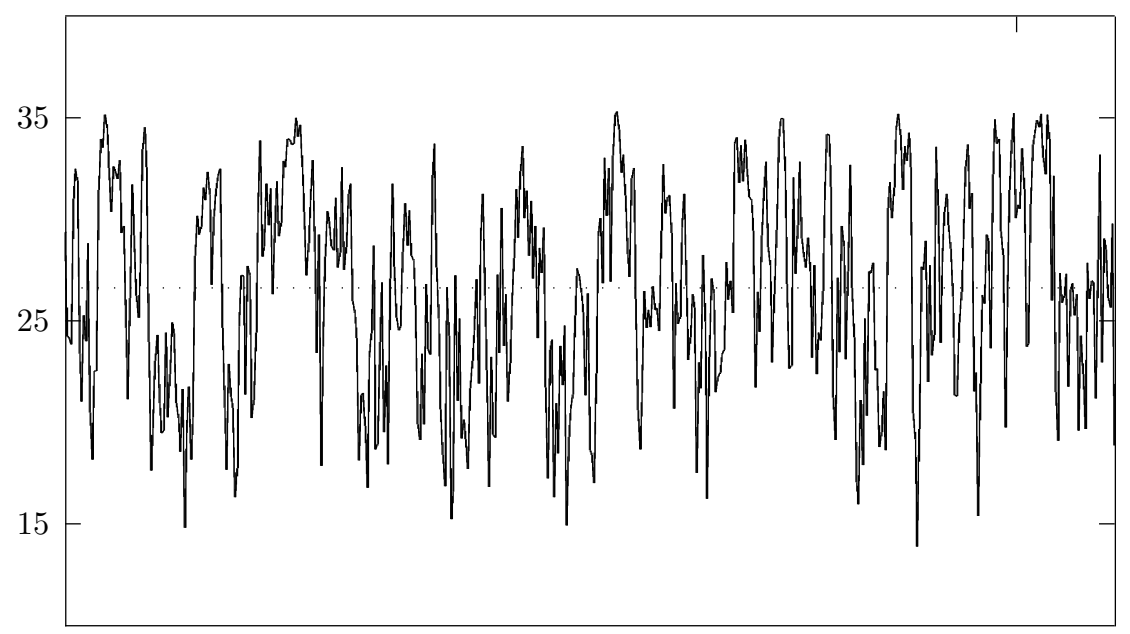

Figure 5: The Price-Dividend Ratio.

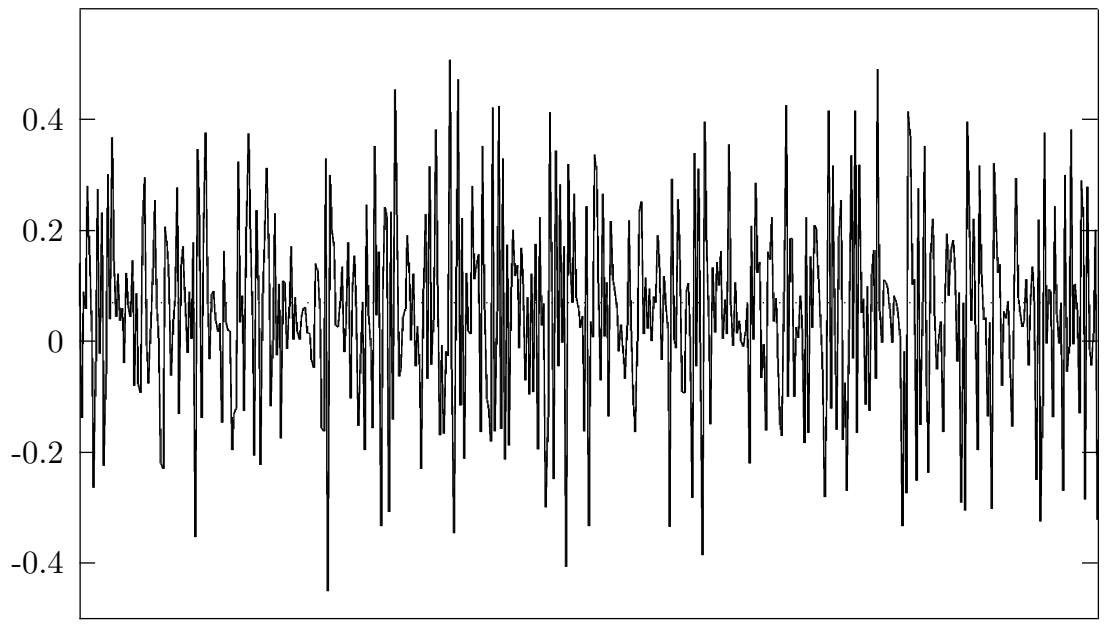

Figure 6: Log of Risky Rates of Return. 